\title{
Revisión taxonómica de Salvia subgénero Calosphace sección Scorodoniae (Lamiaceae), endémica de México
}

\section{Taxonomic revision of Salvia subgenus Calosphace section Scorodoniae (Lamiaceae), endemic to Mexico}

\author{
Edgar Ismael Olvera Mendoza'(D, Brenda Y. Bedolla García² (D) y Sabina I. Lara Cabreral,3 (D)
}

1 Universidad Michoacana de San Nicolás de Hidalgo, Facultad de Biología, Laboratorio de Sistemática Molecular de Plantas, Ciudad Universitaria, Francisco J. Mújica, s.n., Edif. B2-3er piso, Colonia Felicitas del Río, Apdo. postal. 58066, Morelia, Michoacán, México.

2 Instituto de Ecología, A.C., Centro Regional del Bajío, Apdo. postal 386, 61600 Pátzcuaro, Michoacán, México.

3 Autor para la correspondencia: slaracabrera@gmail.com

Citar como:

Olvera Mendoza, E. I., B. Y. Bedolla García y S. I. Lara Cabrera. 2017. Revisión taxonómica de Salvia subgénero Calosphace sección Scorodoniae (Lamiaceae), endémica de México. Acta Botanica Mexicana 118: 7-39. DOI: http://dx.doi.org/10.21829/abml18.2017.1198

Recibido: 26 de abril de 2016.

Revisado: 6 de julio de 2016.

Aceptado: 13 de septiembre de 2016.

$\mathrm{DOI}$

http://dx.doi.org/10.21829/abm118.2017.1198

\section{Resumen:}

Antecedentes y Objetivos: Se reevalúa la sección mexicana Scorodoniae de Salvia subgénero Calosphace. Como parte de los esfuerzos para conocer la flora mexicana varios autores se encuentran revisando la circunscripción de las secciones de Calosphace sensu Epling, incluyendo sus caracteres diagnósticos y la descripción de sus especies. Aún con el breve tratamiento de Turner permanecen algunas especies de difícil determinación en Salvia secc. Scorodoniae. El objetivo de este trabajo fue realizar una diagnosis para Scorodoniae, proporcionar descripciones para cada especie, información sobre sinonimia, ejemplares tipo, así como una clave de identificación y mapas de distribución.

Métodos: Se revisaron 460 especímenes de Salvia secc. Scorodoniae depositados en los herbarios EBUM, ENCB, IEB, MEXU y UAMIZ. La identificación se realizó con ayuda de tratamientos taxonómicos, protólogos y revisión de ejemplares tipo.

Resultados clave: Se sinonimiza a $S$. tepicensis en $S$. aequidistans. Se reconocen como especie $S$. dugesii y $S$. gonzalezii que habían sido tratadas como sinónimos de $S$. melissodora y $S$. pannosa respectivamente. Se incorpora a esta sección a Salvia fruticulosa, originalmente ubicada en la sección Tomentellae.

Conclusiones: Se reconocen en Salvia sección Scorodoniae 16 especies, las cuales se caracterizan por tener lámina foliar deltoide, ovada a ovado-lanceolada o lanceolada elíptica, con el haz bulladorugoso y flores pequeñas.

Palabras clave: distribución, México, revisión taxonómica, sinonimia.

\section{ABSTRACT:}

Background and Aims: The Mexican section Scorodoniae, of Salvia subgenus Calosphace is reviewed. Contributing to the efforts to know the Mexican flora several sections sensu Epling are being reviewed by different authors, including diagnostic characters and species descriptions. Even with Turner's short treatment of Salvia sect. Scorodoniae several species remained difficult to identify. The objective of this research was to diagnose Scorodoniae, provide species descriptions, synonyms, type specimens, an identification key and distribution maps.

Methods: Four hundred and sixty specimens of Salvia secc. Scorodoniae deposited at EBUM, ENCB, IEB, MEXU y UAMIZ were reviewed. Identification was made using several taxonomic treatments, protocols and type specimens.

Key results: Salvia tepicensis is a synonym of $S$. aequidistans. Salvia dugesii and $S$. gonzalezii are recognized as species and no longer treated as synonyms of $S$. melissodora y $S$. pannosa respectively. Salvia fruticulosa previously classified in sect. Tomentellae is now placed in Scorodoniae. Conclusions: Sixteen species of Salvia section Scorodoniae are recognized, characterized by the deltoid, ovate to ovate-lanceolate or elliptic-lanceolate lamina, with bullate-rugose upper surface, and their small flowers.

Key words: distribution, Mexico, synonymy, taxonomic revision. 


\section{INTRODUCCIÓN}

El género Salvia L. se considera un género gigante (Frodin, 2004) por contar con cerca de 1000 especies; se ubica en la familia Lamiaceae, subfamilia Nepetoideae y tribu Mentheae (Ramamoorthy y Elliott, 1998). Además de su gran diversidad en el mundo, varias de las especies de Salvia cuentan con potencial económico por sus propiedades medicinales, culinarias u ornamentales (Yagi et al., 1989; Ahmed et al., 1994; Guillén et al., 1996; Chen et al., 1999; Grundmann et al., 2007; Kamatou et al., 2008).

Una muestra de la complejidad de Salvia es su clasificación en cinco subgéneros: Audibertia (Benth.) Epling, Calosphace (Benth.) Epling, Salvia (Benth.) Epling, Sclarea (Benth.) Epling y Leonia (Benth.) Epling (Bentham, 1836, 1876; Epling, 1939). Calosphace es el subgénero más grande con ca. 500 especies, propias del continente americano, encontrándose desde el suroeste de EUA hasta Argentina (Ramamoorthy y Elliott, 1998). Se distingue del resto de los subgéneros por presentar las dos ramas posteriores de los conectivos fusionadas, aunque secciones como Hastatae (7 especies), Blakea (4), Standleyana (1) y Axillares (1) no las presentan completamente fusionadas (Walker, 2006). En México se distribuyen ca. 312 especies, de las cuales $88 \%$ son endémicas y representan 60 de las secciones sensu Epling (Ramamoorthy y Elliott, 1998). Epling (1939) dividió a Calosphace en 93 secciones, posteriormente incrementándolas hasta 104 (Epling, 1940, 1941, 1944, 1947, 1951; Epling y Mathias, 1957).

La clasificación seccional de Epling (1939) se continúa utilizando por ser el único tratamiento comprensivo para Calosphace, aunque varios autores han criticado la pertinencia y definición de las secciones, por la homoplasia en varios de los caracteres, la distribución disyunta de algunas secciones y casos de sinonimia de especies ubicadas en secciones distintas (Standley y Williams, 1973; Ramamoorthy, 1984a). A pesar de que a la fecha no se cuenta con una revisión para Calosphace posterior a Epling (1939), en años recientes se han reevaluado 18 de las 104 secciones, principalmente con evidencia morfológica: Dusenostachys Epling (Reisfield, 1987), Nobiles (Benth.) Epling (Santos, 1991; Santos y Harley, 2004), Longipes Epling (Fernández-Alonso, 1995), Rudes (Benth.) Epling (Santos, 1996), Ekmania Epling (Torke, 2000), Secundae Epling (Santos, 2004) y Siphonantha Epling (Fernández-Alonso, 2006). De las secciones endémicas para México o mayormente mexicanas, se han estudiado Farinaceae (Benth) Epling (Peterson, 1978; Turner 2008), Sigmoideae Epling (Espejo y Ramamoorthy, 1993), Axillares Epling (Turner 1996), Farinaceae (Benth.) Epling (Turner, 2008), Scorodoniae Epling (Turner, 2009), Iodanthae Epling, Polystachyae Epling y Purpureae Epling (BedollaGarcía, 2012), Lavanduloides Epling (Fragoso, 2014) y Membranaceae (Benth.) Epling (González, 2014).

En el presente trabajo se contribuye al conocimiento taxonómico de Calosphace, con la revisión y evaluación de la sección mexicana Scorodoniae, en la cual, aunque Turner (2009) realizó una breve discusión de la sección e incorporó en ésta a Salvia pericona B.L. Turner y Salvia tenorioi Ramamoorthy ex B.L. Turner, la delimitación e identificación de Scorodoniae y sus especies no fueron totalmente esclarecidas.

\section{Materiales y MÉTOdOS}

Se revisaron 460 ejemplares depositados en los herbarios EBUM, ENCB, IEB, MEXU y UAMIZ. La identificación se realizó utilizando las principales claves y tratamientos (Epling, 1939, 1940, 1941; Standley y Williams, 1973; Turner, 2009; Rzedowski et al., 2010). Adicionalmente se consultaron los protólogos de todas las especies (Lagasca, 1816; Lamark y Poiret, 1817; Bentham, 1836; Sessé y Mociño, 1894; Fernald, 1900, 1901; Brandegee, 1908; Fernald, 1910; Standley y Williams, 1973; Turner, 2009) y se observaron ejemplares tipo en JSTOR Global Plants (JSTOR, 2000-2016).

Finalmente se realizaron mapas de distribución de las especies, utilizando la información de las etiquetas de colecta; se georreferenciaron los ejemplares. En los casos en que la etiqueta no presentaba información de latitud y longitud se utilizó Google Maps (Google, s.f.) 
obteniendo las coordenadas a partir de la localidad citada. Los mapas se generaron en DIVA-GIS versión 7.5 (Hijmans, 2012).

\section{Historia taxonómica de la sección Scorodoniae}

La historia de Scorodoniae comienza en el siglo XIX con la descripción de Salvia melissodora Lag. (Lagasca, 1816) y $S$. scorodoniaefolia Desf. ex Poir. (Lamarck y Poiret, 1817). Bentham (1836) realiza el primer trabajo de recopilación para Salvia en el que describe dentro de su sección Calosphace subsección Brachyanthae a S. breviflora Moc. \& Sessé ex Benth., S. fruticulosa Benth. y $S$. keerlii Benth., además, considera como sinónimo de $S$. scorodonia Desf. ex Poir. a S. melissodora.

Fernald (1900) describe tres nuevas especies: $S$. aequidistans Fernald, S. conzatti Fernald, S. nelsonii Fernald y una variedad, S. scorodoniaefolia var. crenaea Fernald. Adicionalmente distingue series dentro de la sección Brachyanthae de Bentham, ubicando las especies en Brachyanthae serie Scorodoniae, con excepción de $S$. breviflora en la serie Vulgares (Cuadro 1). Posteriormente describe a $S$. albicans Fernald, S. dugesii Fernald, S. gonzalezii Fernald, S. rupicola Fernald y S. tepicensis Fernald y las ubica en Brachyanthae serie Scorodoniae. La última especie del grupo, $S$. ramosa Brandegee, fue descrita en 1908 y ubicada por Fernald (1910) en Brachyanthae serie Scorodoniae.

En su revisión de Calosphace Epling (1939) asciende la sección de Bentham a subgénero. En su clasificación seccional crea y delimita la sección Scorodoniae con 12 especies incluyendo cuatro nuevas: $S$. occidua Epling, $S$. paupercula Epling, $S$. reducta Epling y $S$. variana Epling. Considera como sinónimos de S. breviflora a S. albicans y $S$. nelsonii; en $S$. pannosa Fernald considera sinónimo a $S$. gonzalezii Fernald; como sinónimo de $S$. melissodo$r a$ a $S$. dugesii, S. microphylla Sessé et Moc. (non Salvia microphylla Kunth.), S. scorodonia Benth., S. scorodoniaefolia y $S$. scorodoniaefolia var. crenae; finalmente $S$. scorodoniaefolia var. subsessilis Benth. es ubicada como sinónimo de $S$. tepicensis.
En la publicación de Epling (1939) un aparente error de imprenta omite en el nombre de la sección la "e" de Scorodoniae nombrándola "Scorodonia". Este error se ha replicado en trabajos posteriores; sin embargo, de acuerdo con el artículo 60.1 del Código Internacional de Nomenclatura Botánica (McNeill et al., 2012) la tipografía correcta para la sección debe ser "Scorodoniae".

Posteriormente, Epling (1941) incorpora a Scorodoniae las especies que había clasificado en la sección Uricae (Epling, 1939): Salvia amarissima Ortega y S. urica Epling. Hasta ese momento la sección incluía solo especies mexicanas, con la excepción de $S$. reducta cuya distribución llega hasta Guatemala; sin embargo, en la Flora de Guatemala (Standley y Williams, 1973) se considera que Salvia reducta es sinónimo de $S$. polystachia Cav., quedando Scorodoniae como sección endémica a México. Turner (2009) incorpora en Scorodoniae tres nuevas especies: S. boegei Ramamoorthy (1984b), S. pericona y $S$. tenorioi, además incluye a $S$. ramosa como sinónimo de $S$. variana y excluye de Scorodoniae a $S$. amarissima y S. urica (previamente Uricae). Recientemente se describió una nueva especie para Scorodoniae, Salvia evadens J.G. González y Art. Castro (González y Castro, 2016).

\section{Resultados}

\section{Morfología}

El hábito de la mayoría de las especies de la sección Scorodoniae es arbustivo, de 0.5 hasta $3.5 \mathrm{~m}$. de altura, ocasionalmente herbáceo perenne ( $S$. evadens, S. pericona y S. occidua).

La presencia de tricomas simples, glandular-capitados y dendríticos en órganos vegetativos y reproductivos (Fig. 1) ayuda a reconocer a las especies de Scorodoniae. Los tricomas dendríticos varían en la longitud de las ramas laterales respecto a la principal; los dendríticos largos con ramas laterales de casi $1 / 2$ del largo de la rama principal, en $S$. dugesii, S. paupercula, $S$. ramosa y $S$. variana (Fig. 1I) y los dendríticos cortos de $S$. fruticulosa (Fig. 1J) que presentan ramas laterales de 1/4 del largo de la rama principal. 


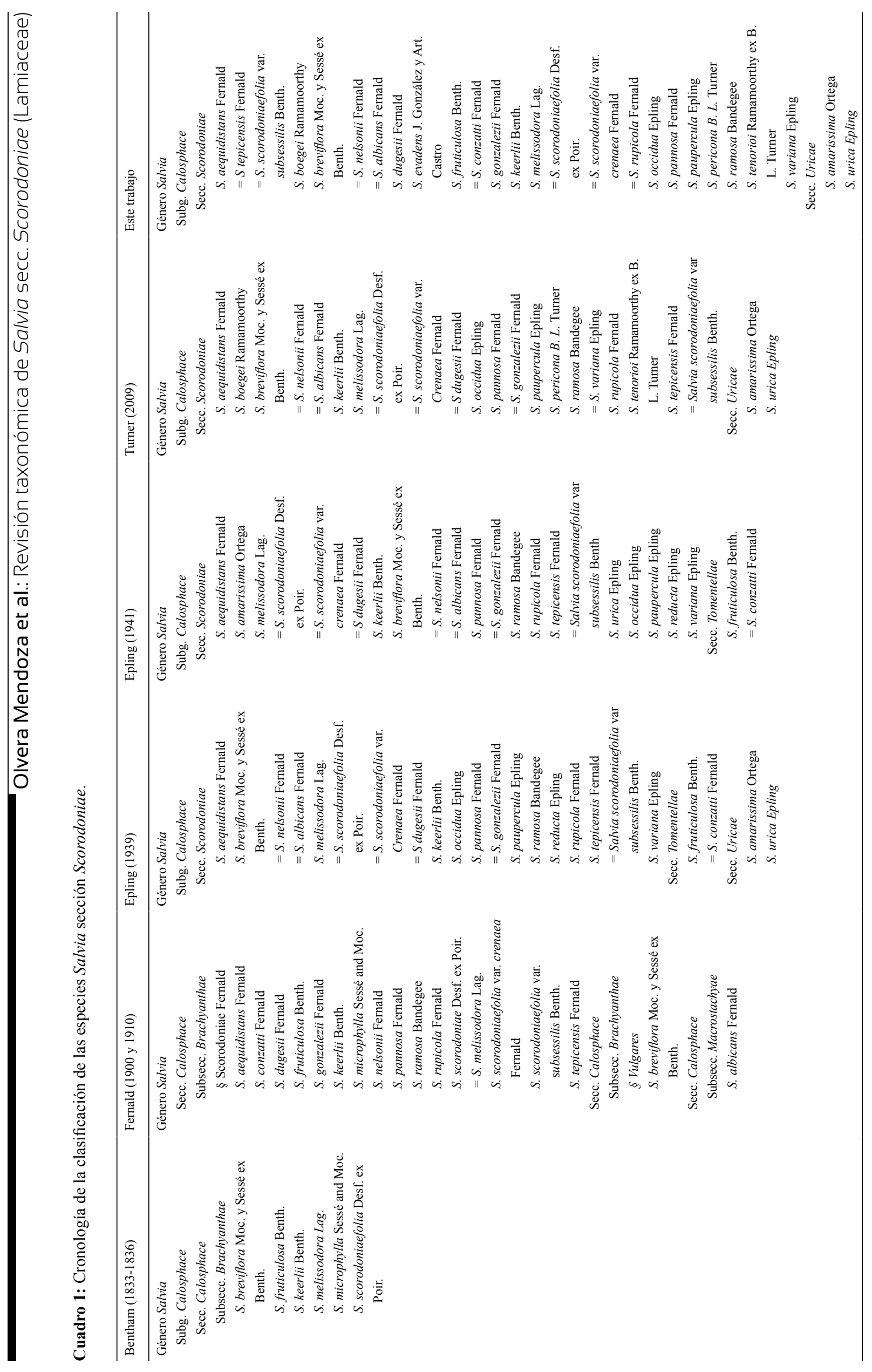




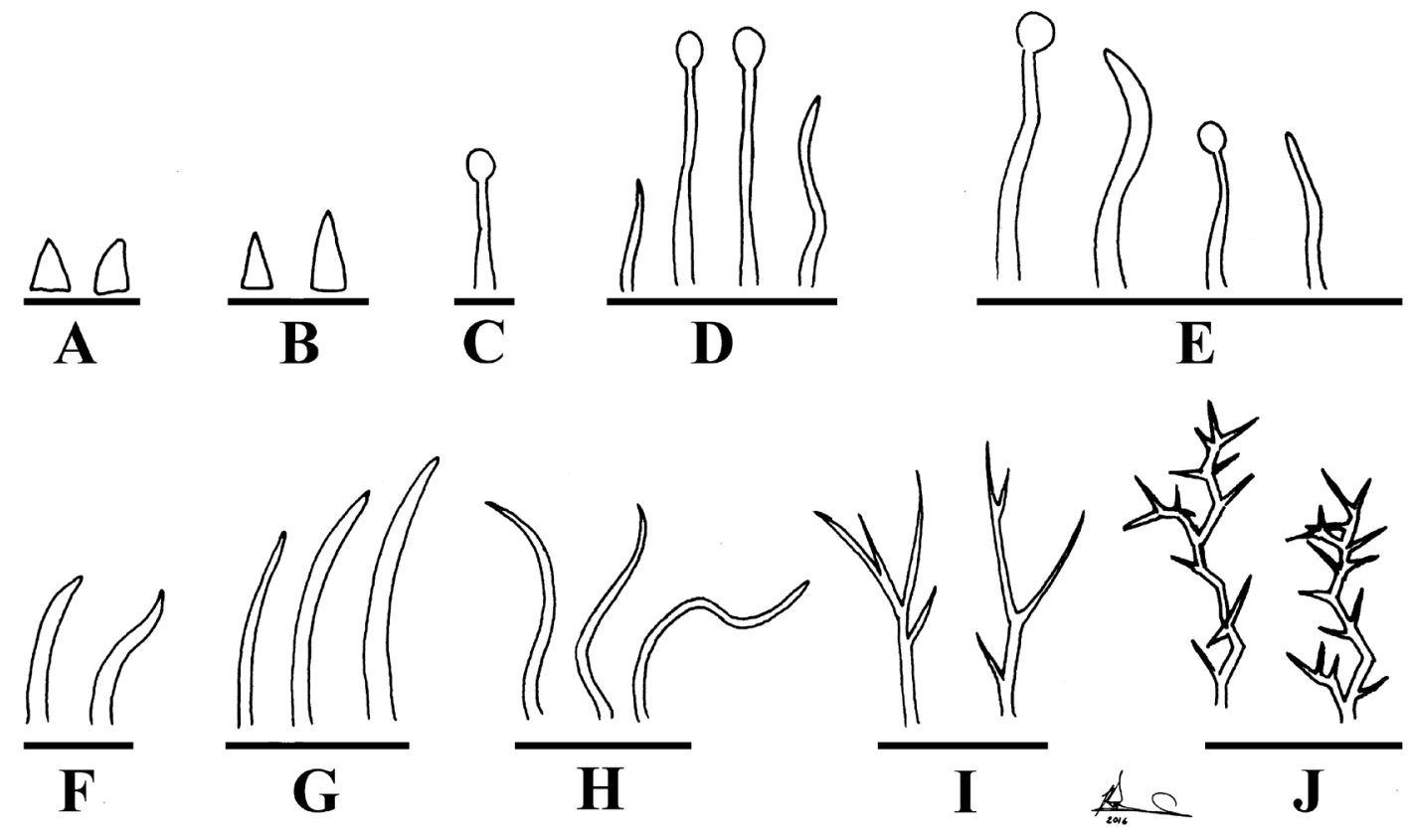

Figura 1: Forma de los tricomas del cáliz de Salvia L. sección Scorodoniae: A. S. pericona B.L. Turner; B. S. pannosa Fernald; C. S. evadens J.G. González \& Art. Castro; S. paupercula Epling y S. tenorioi Ramamoorthy ex B.L. Turner; D. S. aequidistans Fernald y S. gonzalezii Fernald; E. S. melissodora Lag.; F. S. occidua Epling; G. S. keerlii Benth.; H. S. breviflora Moc. \& Sessé y S. boegei Ramamoorthy; I. S. dugesii Fernald, S. ramosa Brandegee y $S$. variana Epling; J. S. fruticulosa Benth. Ilustrado por José Manuel Ramírez Amezcua.

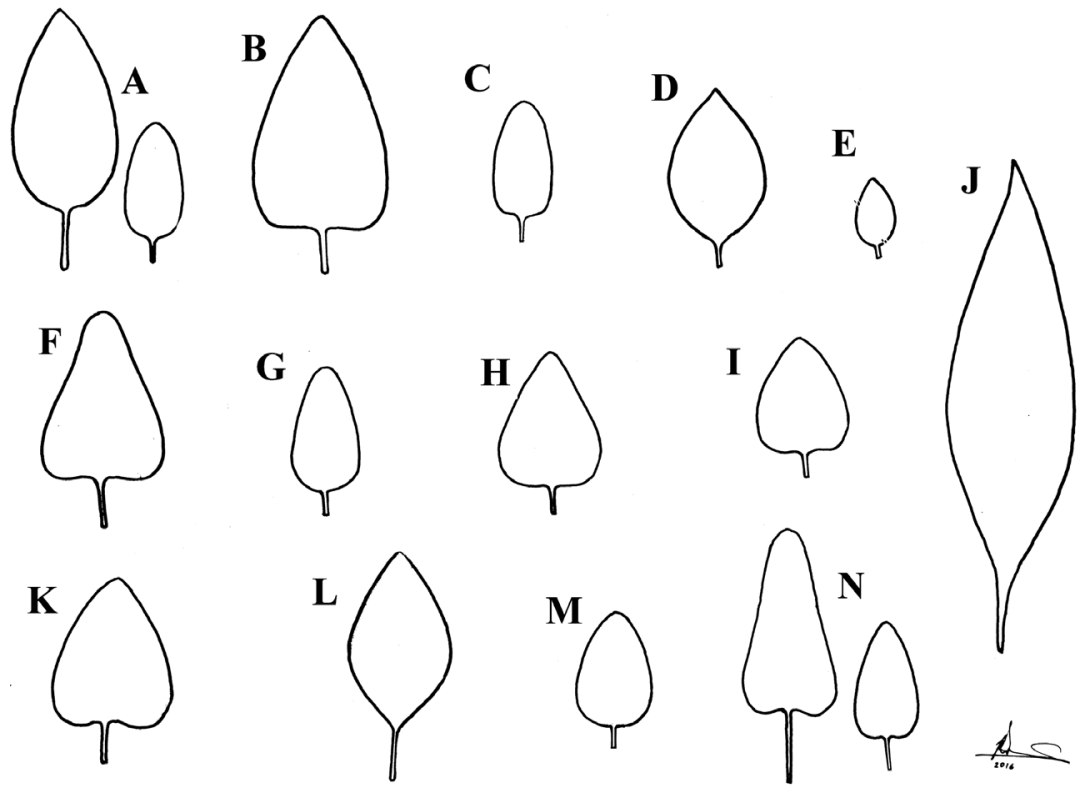

Figura 2: Forma de la lámina foliar de Salvia L. sección Scorodoniae: A. S. fruticulosa Benth.; B. S. dugesii Fernald; C. S. paupercula Epling; D. S. boegei Ramamoorthy; E. S. tenorioi Ramamoorthy ex B.L. Turner; F. S. pericona B.L. Turner, G. S. ramosa Brandegee; H. S. gonzalezii Fernald y $S$. variana Epling; I. S. evadens J.G. Gonzalez \& Art. Castro y S. melissodora Lag.; J. S. occidua Epling; K. S. keerlii Benth.; L. S. breviflora Moc. \& Sessé; M. S. aequidistans Fernald; N. S. pannosa Fernald.Las inflorescencias son indefinidas, en racimos o panículas, espiciformes, de 3 a 30 cm de largo, con verticilastros a lo largo del raquis, distanciados 2 a $33 \mathrm{~mm}$ en la parte media, de 2 a 12 flores pediceladas. Las brácteas en las especies de Scorodoniae son pronto deciduas, ovadas o acuminadas, con el margen entero. Ilustrado por José Manuel Ramírez Amezcua. 
Los tallos son ramificados, cuando jóvenes presentan tricomas simples, glandular-capitados o dendríticos, conforme maduran las ramas comienzan a ser glabrescentes. La longitud de los tricomas normalmente es de $0.1 \mathrm{a}$ $0.6 \mathrm{~mm}$, encontrándose los más largos en S. pericona $(0.6$ $\mathrm{mm})$ y ocasionalmente en $S$. keerlii $(0.4$ a $0.6 \mathrm{~mm})$.

Las láminas foliares se caracterizan por presentar el haz bullado-rugoso, margen aserrado y ápice agudo ( $S$. boegei, S. breviflora, S. fruticulosa, S. melissodora, S. occidua y $S$. pericona), agudo a obtuso (S. aequidistans, $S$. dugesii, S. gonzalesii, S. evadens, S. keerlii, S. pannosa, $S$. ramosa, $S$. tenorioi y $S$. variana) o siempre obtuso en $S$. paupercula. La forma de la lámina foliar es deltoide, ovada a ovado-lanceolada y lanceolada elíptica únicamente en S. occidua; la base de la lámina generalmente es cordada, con algunas láminas truncas o redondeadas y cuneada en $S$. breviflora, S. fruticulosa y S. occidua. La longitud de la lámina foliar es de 0.5 a $12 \mathrm{~cm}$ de largo y 0.5 a 4.5 cm de ancho; en $S$. occidua se encuentran las más largas $(8$ a $12 \mathrm{~cm})$, y las más cortas en $S$. gonzalezii $(1$ a $2.2 \mathrm{~cm})$, $S$. paupercula $(1.5$ a $2 \mathrm{~cm})$ y $S$. tenorioi $(0.6$ a $2 \mathrm{~cm})$. El peciolo es de 2 a $40 \mathrm{~mm}$ de largo, con los más cortos en $S$. paupercula (1 a $8 \mathrm{~mm}), S$. occidua $(5$ a $7 \mathrm{~mm})$ y $S$. gonzalezii (5.5-10 mm), y los más largos de 15 a $40 \mathrm{~mm}$ en $S$. keerlii, S. melissodora, S. pannosa y S. pericona (Fig. 2).

Flores bilabiadas con pedicelo, corolas generalmente de color azul a morado, blancas en $S$. occidua y $S$. pericona, ocasionalmente también en $S$. breviflora y $S$. pannosa; amarillo-rojizas en $S$. tenorioi y rosa a guinda en $S$. variana. Flores de 6 a $23 \mathrm{~mm}$ de largo, la mayor variación en la longitud de la flor se encuentra en $S$. melissodora (6 a $18 \mathrm{~mm}$ ) y $S$. dugesii (5 a $15 \mathrm{~mm}) ; S$. ramosa presenta las flores más pequeñas $(6.5$ a $8 \mathrm{~mm})$, mientras que las de $S$. pericona $(16 \mathrm{~mm})$ y $S$. evadens $(23 \mathrm{~mm})$ son las más grandes. El labio superior es galeado, en el dorso se presentan tricomas simples ( $S$. aequidistans, S. boegei, S. gonzalezii, S. keerlii, S. occidua, S. pannosa, S. pericona), glandular-capitados (S. dugesii, $S$. melissodora, S. tenorioi) y dendríticos (S. fruticulosa, $S$. ramosa), en $S$. variana se pueden encontrar tricomas simples y glandular-capitados a la vez; el labio inferior es trilobado, generalmente más largo que el superior y ocasionalmente son subiguales. Al interior del tubo de la corola generalmente se encuentran de 2 a 4 papilas excepto en $S$. evadens, S. keerlii, S. pannosa y S. pericona que carecen de papilas.

Cálices tubulares a campanulados, de 3.5 a 11 $\mathrm{mm}$ de largo, los más largos se encuentran en $S$. evadens (7 a $7.6 \mathrm{~mm})$ y $S$. pericona $(8$ a $11 \mathrm{~mm})$; lóbulos obtusos o ligeramente agudos, el lóbulo superior entero con 5 a 7 venas, el lóbulo inferior bífido, la mayoría de las especies con pubescencia vilosa, algunas canescente (S. boegei, S. breviflora y $S$. fruticulosa) y glabrescente (S. gonzalezii y S. pannosa); con tricomas simples ( $S$. boegei, S. breviflora, S. keerlii, S. occidua, S. paupercula y $S$. pericona), glandular-capitados (S. tenorioi), simples y/o glandular-capitados (S. aequidistans, S. gonzalezii, S. melissodora y S. pannosa) o dendríticos (S. dugesii, $S$. fruticulosa, S. ramosa y S. variana) (Fig. 1).

Androceo con dos estambres fértiles, anteras elipsoides, dorsifijas y monotecas, dispuestos en la parte anterior de la corola, veccinario con un diente retrorso y dos estaminodios en el interior del tubo de la corola. El gineceo está constituido por un estilo barbado, formando dos ramas estigmáticas, la rama posterior de casi el doble de largo que la anterior, ginobásico, ovario tetralobulado, tetralocular y tetraovulado. Mericarpos ovoides, 1 a 3.5 $\mathrm{mm}$ de largo por 0.8 a $2 \mathrm{~mm}$ de ancho, marrones claro, lisos, glabros.

\section{Distribución y fenología}

Las especies de Scorodoniae se distribuyen en cinco de las regiones fisiográficas de México sensu Rzedowski (1978); Sierra Madre Occidental, Faja Volcánica Transmexicana, Sierra Madre Oriental, Altiplano Mexicano y Sierra Madre del Sur (Fig. 3). En altitudes de 1500 a 2500 m, excepto $S$. aequidistans (200 a $1400 \mathrm{~m}$ ), S. evadens (1150 a $1400 \mathrm{~m}), S$. gonzalezii (1200 a $1400 \mathrm{~m}$ ) y $S$. occidua (200 a $900 \mathrm{~m}$ ), que se encuentran a menor altitud que las demás especies, mientras que a mayor altitud se localizan S. pannosa y S. keerlii, alcanzando los 2900 y $3100 \mathrm{~m}$ respectivamente (Fig. 4). 


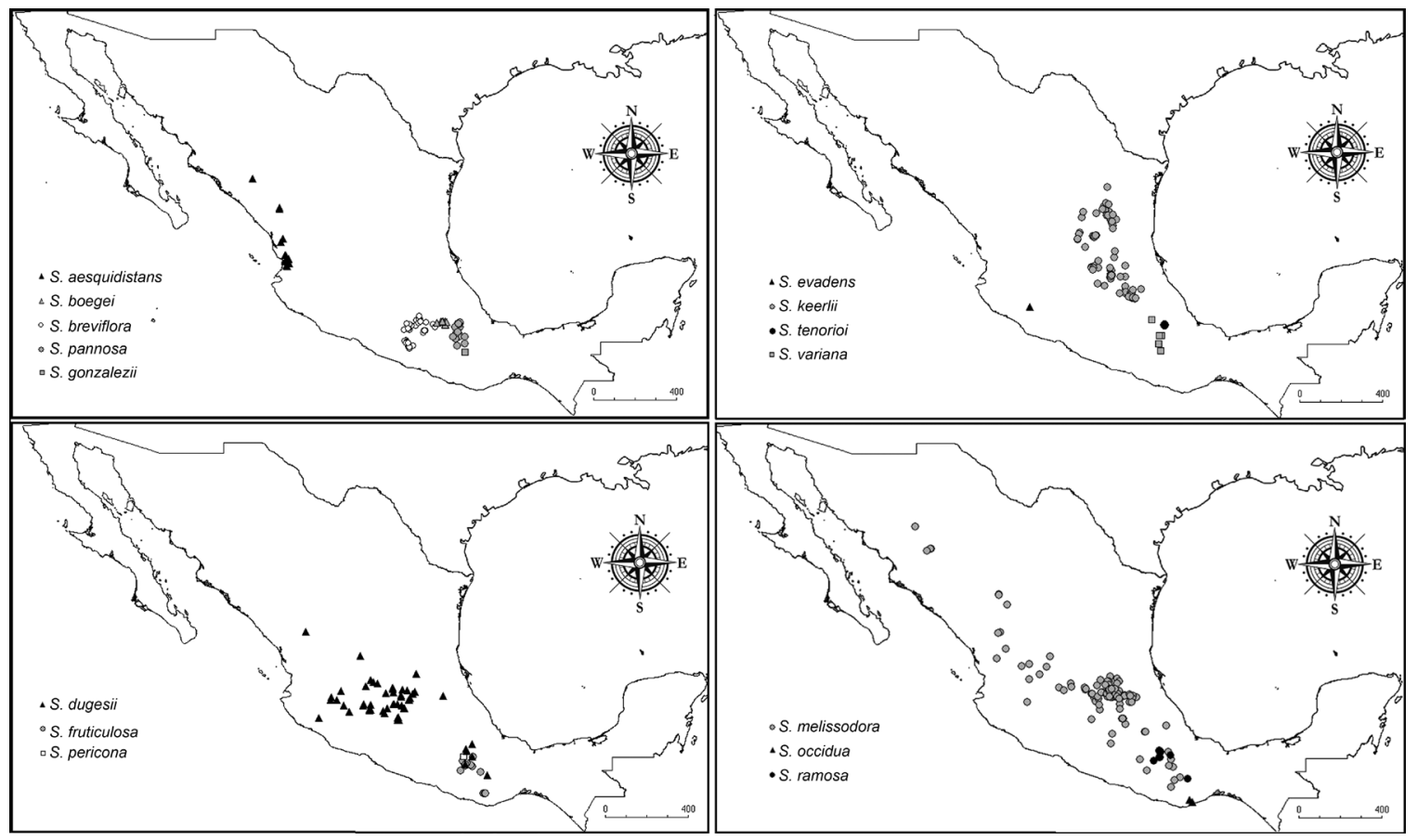

Figura 3: Distribución de las especies de Salvia L. sección Scorodoniae.

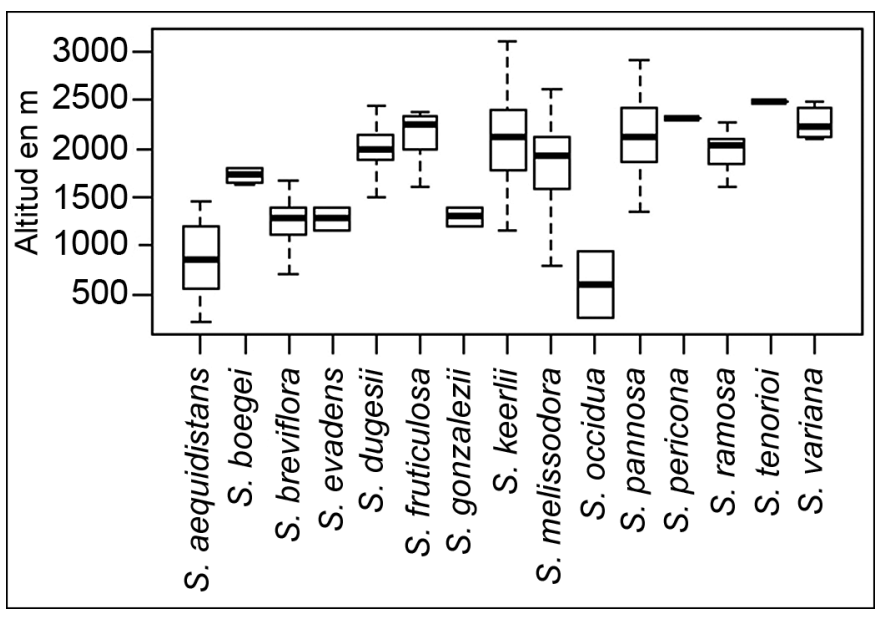

Figura 4: Rango altitudinal de distribución de las especies de Salvia L. sección Scorodoniae.

De las 16 especies, 13 habitan en matorral xerófilo o bosque tropical caducifolio, aunque también se distribuyen en otros tipos de vegetación, como los bosques templados de Juniperus, Pinus, Quercus, Pinus-Juniperus, PinusQuercus, Quercus-Juniperus o en pastizales secundarios.
Salvia evadens es exclusiva de encinares, $S$. breviflora es endémica del bosque tropical caducifolio y $S$. pericona se restringe al matorral xerófilo. Las especies que habitan en bosques templados, además del matorral xerófilo son $S$. aequidistans, $S$. dugesii, S. fruticulosa, S. keerlii, S. melissodora, S. pericona, S. ramosa, S. tenorioi y S. variana. Algunas especies como $S$. pannosa, S. pericona y $S$. variana habitan también en ecotono entre el bosque de Quercus y el matorral xerófilo. Finalmente $S$. dugesii y S. melissodora también se pueden encontrar en bosques de Quercus muy perturbados o en pastizales secundarios.

Las especies $S$. aequidistans, S. dugesii, S. keerlii y $S$. melissodora muestran un rango de distribución amplio en la República. Salvia aequidistans se encuentra en la Sierra Madre Occidental, desde el Noroeste de Durango hasta Nayarit, mientras que $S$. dugesii se distribuye en el Altiplano Mexicano, sobre la Faja Volcánica Transmexicana y en Oaxaca en la Sierra Madre del Sur. Por su parte, S. keerlii habita en la Sierra Madre Oriental y el Altiplano Mexicano, desde el Sur de Monterrey hasta Hidalgo. La especie de Scorodoniae con más am- 


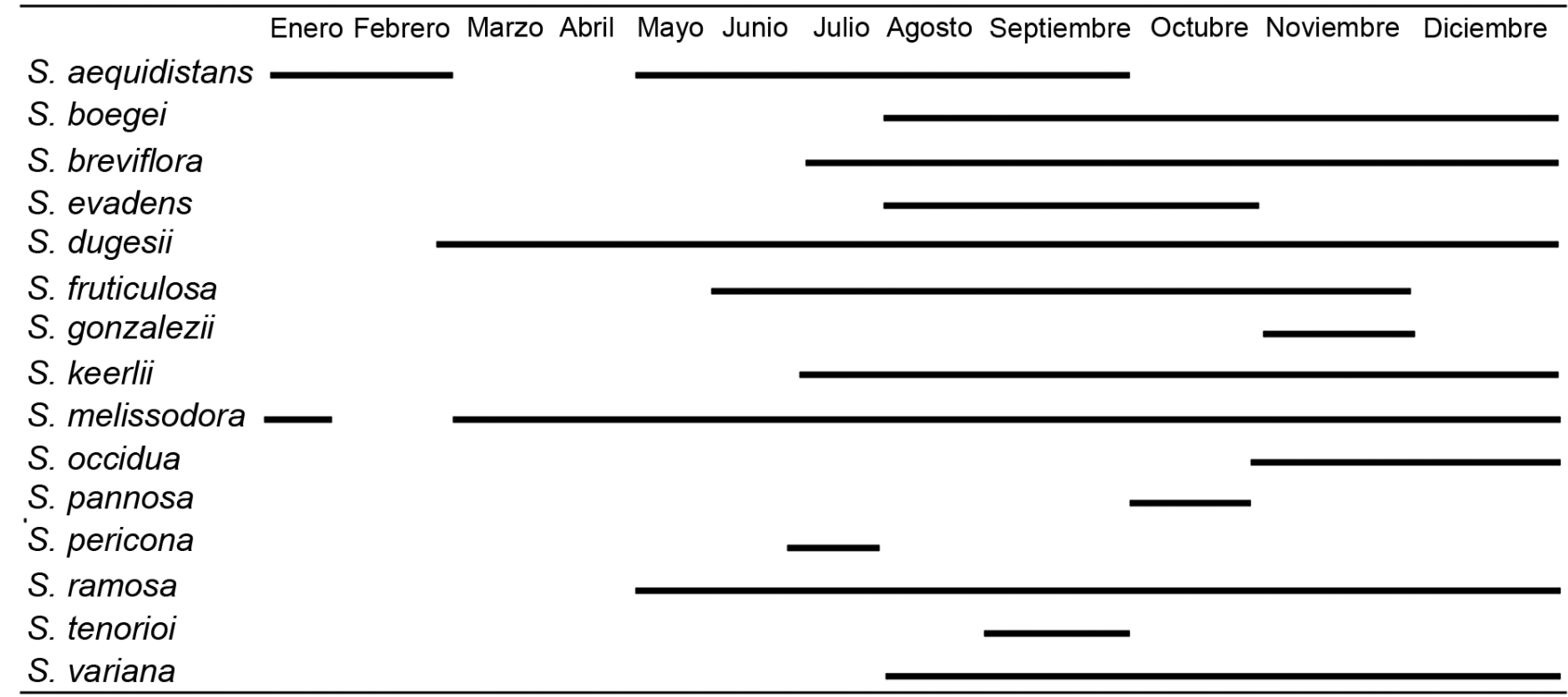

Figura 5: Meses de floración de las especies de Salvia L. sección Scorodoniae.

plia distribución es $S$. melissodora, desde el suroeste de Chihuahua hasta Oaxaca; en la Sierra Madre Occidental, el Altiplano, la Faja Volcánica Transmexicana y la Sierra Madre del Sur. El resto de las Scorodoniae presentan distribución restringida con alto nivel de endemismo (Fig. 3).

Las especies de la sección Scorodoniae florecen principalmente durante la temporada de lluvias de julio a diciembre (Fig. 5). La única especie que se ha visto con flores en los meses de enero y febrero es $S$. aequidistans.

\section{Taxonomía}

Salvia secc. Scorodoniae Epling, Regni Veg. Beih. 110: 166. 1939, descripción enmendada. TIPO: Salvia melissodora Lag. Gen. Sp. Pl. 2. 1816. M. Sessé y Lacasta y J. M. Mociño s.n. (lectotipo: G!)

Arbustos, a veces subarborescentes, rara vez hierbas perennes; el cuerpo vegetativo e inflorescencia cubiertos por tricomas simples, glandular-capitados o dendríticos; lámina foliar generalmente deltoide, ovada, ovado-lanceolada a ovado-oblonga, rara vez lanceolada, lanceolado-elíptica y ocasionalmente orbicular, haz frecuentemente bulladorugoso, verde, envés verde claro o canescente; inflorescencias indefinidas, en racimo o panícula, espiciformes, 3-30 cm de largo, con verticilastros a lo largo del raquis, de apariencia compacta o laxa, cada verticilastro presenta por lo general 6-12 flores pediceladas; brácteas pronto deciduas, rara vez subpersistentes; cáliz tubular a campanulado, con labios caudados; el superior más largo que el inferior o ambos cortos, pubescencia vilosa, canescente y ocasionalmente glabrescente, con tricomas simples, glandular-capitados o dendríticos, el superior con 5-7 venas; corola azul a morada o blanca, rara vez amarilla, rojiza, rosa o guinda, simpétala y bilabiada, $6-23 \mathrm{~mm}$ de largo; tubo ventricoso, con frecuencia adornado cerca de la base, en la parte interna, con dos a cuatro papilas, rara vez desnudo, labio superior más corto, en raras ocasiones subiguales y cubriendo a los estambres; androceo con dos estambres fértiles, anteras elipsoides, dorsifijas y monotecas, dispuestos en la parte anterior de la corola, veccinario con un diente retrorso y dos estaminodios en el interior del tubo de la corola; gineceo con estilo bífido, barbado, ginobásico, ovario tetralobulado, tetralocular y tetraovulado; mericarpos ovoides, marrón claro. 


\section{Clave para la identificación de Salvia sección} Scorodoniae

1a. Indumento del cáliz con tricomas simples y/o glandular-capitados 2

1b. Indumento del cáliz con tricomas dendríticos ....... 13

2a. Tricomas del cáliz glandular-capitados .................... 3

2b. Tricomas del cáliz no glandular-capitados .............. 9

3a. Corola blanca o azul a morada ................................. 4

3b. Corola amarilla a rojiza ............................ S. tenorioi

4a. Lámina foliar discolora, el envés canescente, con pubescencia densa que cubre toda la superficie ....... 5

4b. Lámina foliar concolora, el envés glabrescente o tomentuloso, la pubescencia no cubre completamente la superficie ... 6

5a. Lámina foliar ovado-lanceolada a lanceolada, 1.5 a $4.5 \mathrm{~cm}$ de largo S. pannosa

5b. Lámina foliar deltoide a ovada, 1 a $2.2 \mathrm{~cm}$ de largo ... S. gonzalezii

6a. Con tricomas glandular-capitados en el margen del labio superior de la corola 7

6b. Sin tricomas glandular-capitados en el margen del labio superior de la corola 8

7a. Peciolos cortos de 1 a $8 \mathrm{~mm}$ de largo ... S. paupercula

7b. Peciolos largos de 9 a $12 \mathrm{~mm}$ de largo ...S. melissodora

8a. Flor de longitud menor de $15 \mathrm{~mm}$..... S. aequidistans

8 b. Flor de longitud mayor de $15 \mathrm{~mm}$ S. evadens

9a. Lámina foliar concolora, base cuneada 10

9b. Lámina foliar discolora, base cordada, truncada o redondeada 12

10a. Lámina foliar lanceolado-elíptica, de más de $8 \mathrm{~cm}$ de largo S. occidua

10b.Lámina foliar ovada a redondeada, de menos de $7 \mathrm{~cm}$ de largo 11

11a. Lámina foliar de longitud mayor de $4.5 \mathrm{~cm}$

S. breviflora

11b. Lámina foliar de longitud menor de $4.5 \mathrm{~cm}$

S. boegei

12a.Flores blancas, lámina foliar con envés densamente canescente

S. pericona

12b.Flores azules o moradas, lámina foliar con envés viloso

S. keerlii 13a. El dorso del labio superior de la corola con tricomas dendríticos 14

13b. El dorso del labio superior de la corola sin tricomas dendríticos 15

14a. Cáliz con tricomas dendríticos de 0.1 a $0.3 \mathrm{~mm}$ de largo, con glándulas sésiles rojizas S. fruticulosa

14b. Cáliz con tricomas dendríticos de 0.3 a $0.8 \mathrm{~mm}$ de largo, sin glándulas sésiles rojizas S. ramosa

15a. Envés de la lámina foliar viloso S. dugesii

15b.Envés de la lámina foliar densamente canescente ...... S. variana

1) Salvia aequidistans Fernald, Proc. Amer. Acad. Arts Sci. 35(25): 512. 1900. TIPO: MÉXICO. Sinaloa, entre Rosario y Colomas, J. N. Rose 1609 (holotipo: GH!, isotipos: K!, MEXU!, NY!, US!) = Salvia scorodoniaefolia var. subsessilis Benth., Prodr. (DC). 12: 316. 1848. TIPO: MÉXICO. Colima, Manzanillo, A. Barclay s.n. (holotipo: $\mathrm{K} !)=$ Salvia tepicensis Fernald, Proc. Amer. Acad. Arts Sci. 45: 420. 1910. TIPO: MÉXICO. Nayarit, Tepic, E. Palmer 1984 (holotipo: GH!, K, isotipos: ARIZ!, CAS!, F!, P!), syn. nov.

Plantas arbustivas, de $0.5-1 \mathrm{~m}$ de alto; tallos poco ramificados, entrenudos 3-8 cm, vilosos cuando jóvenes, con tricomas simples y/o glandular-capitados, $0.2-0.9 \mathrm{~mm}$ de largo, glabrescente en la madurez; peciolo $2-7.5 \mathrm{~mm}$ de largo, viloso, con tricomas simples, glandular-capitados o ambos, algunos cortos, 0.2-0.4 mm, otros largos, 0.5-0.9 $\mathrm{mm}$; lámina foliar concolora, deltoide a ovada, $1.4-3.5 \mathrm{~cm}$ de largo, 1.2-2.7 cm de ancho, ápice agudo a obtuso, base truncada, redondeada, rara vez cordada, margen aserrado, haz bullado-rugoso, viloso a glabrescente, con tricomas simples, (0.2)0.5-1 mm de largo, envés viloso a glabrescente, con tricomas simples cortos y largos, $0.2-0.5 \mathrm{~mm}$, ocasionalmente con tricomas glandular-capitados, particularmente en el margen; inflorescencia indefinida en racimo terminal, $6-33 \mathrm{~cm}$ de largo, con verticilastros a lo largo del raquis, distanciados $10-28 \mathrm{~mm}$ en la parte media, con 6-10 flores, raquis viloso, con tricomas simples y glandular-capitados, 0.2-0.8 mm de largo; brácteas ova- 
das, marrón claro, pronto deciduas, acuminadas, margen entero, 2.3-3.4 mm de largo, 1.4-2 $\mathrm{mm}$ de ancho, vilosas, con tricomas simples y glandular-capitados, $0.5 \mathrm{~mm}$ de largo; pedicelo 1.5-3.5 mm de largo, viloso, con tricomas simples y glandular-capitados, 0.1-0.5 mm de largo, ocasionalmente solo simples; cáliz tubular, 5-7 mm de largo, 3-4.5 mm de ancho, con labios caudados, el superior con 7 venas, viloso, con tricomas simples o glandular-capitados, 0.2-0.7 mm de largo, ocasionalmente ambos; corola azul a morada, 9-12 $\mathrm{mm}$ de largo; tubo ventricoso, 4.6-6.4 mm de largo, con 2 papilas en su interior; labio superior galeado, 2.7-4.6 mm de largo, viloso, en el dorso con tricomas simples, tricomas glandular-capitados en el margen del labio; el inferior trilobado, 4-8.5 mm de largo, más largo que el superior; androceo con anteras elipsoide, dorsifijas y monotecas, filamento 5.6-6.1 mm de largo, estaminodios 2; gineceo con estilo bífido, barbado, 8.5-9 $\mathrm{mm}$ de largo, rama anterior $0.6-0.8 \mathrm{~mm}$ de largo, rama posterior 2.7-3 mm de largo; mericarpos ovoides, 1-1.2 $\times$ 0.4-0.6 mm, marrones claro, lisos y glabros.

Distribución y ecología: Durango y Nayarit. Encinar arbustivo, bosque tropical caducifolio y en la ecotonía entre estos. Altitud 210 a 1460 m. Floración de mayo a febrero.

En este trabajo se considera a $S$. tepicensis como sinónimo de $S$. aequidistans. Epling (1939) distinguió a $S$. aequidistans por la pubescencia vilosa, con tricomas glandular-capitados en su cuerpo vegetativo y cálices, con distribución en Sinaloa, mientras que en $S$. tepicensis la pubescencia es híspida, con tricomas simples, y ocurre en Nayarit. De acuerdo con nuestras observaciones, hay individuos de Nayarit con tricomas glandular-capitados y pubescencia vilosa, con tricomas simples y glandularcapitados, es decir correspondientes a $S$. aequidistans. Por tal razón, se considera que son una sola especie, que a lo largo de su distribución muestra estos tipos de tricomas, sin un patrón geográfico específico.

Salvia aequidistans se puede confundir con S. evadens por su inflorescencia laxa y la pubescencia del cuer- po vegetativo; sin embargo, se distinguen por el tamaño de las flores, en $S$. aequidistans las flores son más pequeñas (9-12 mm), mientras que $S$. evadens tiene flores más grandes $(17.7-23 \mathrm{~mm})$.

Material examinado. MÉXICO. Durango, municipio Canales, $3 \mathrm{~km}$ de Canales, 2.VIII.1990, O. Bravo B. 1094 (IEB). Municipio El Salto, $8 \mathrm{~km}$ al E de Palmito, carretera Mazatlán - Durango, 10.III.1985, P. Tenorio L. 8231 (MEXU). Municipio Pueblo Nuevo, between Coyotes and Llano Grande along Mexican highway 40 between Mazatlán and Durango, 24.VIII.1986, D. E. Breedlove 63092 (MEXU). Nayarit, municipio Acaponeta, $3.3 \mathrm{~km}$ al SO de La Mesa de Pedro y Pablo, 12.IX.1989, O. Téllez V. 12025 (MEXU); $1 \mathrm{mi} \mathrm{SW}$ of intersection of San Blas road with Tepic - Mazatlán road, 25.VI.1972, G. L. Webster 17094 (MEXU). Municipio Compostela, camino de Compostela hacia Tepic entre el km 11 y 13, 30.X.2014, E. I. Olvera M. 22 (EBUM); La Mesilla, $40 \mathrm{~km}$ al S de Compostela, 22.VIII.1984, R. Hernández M. 9697 (MEXU); 11 km al SO de Compostela, camino a Mazatlán, 16.I.1988, O. Téllez V. 11221 (MEXU); $25 \mathrm{~km}$ by road $\mathrm{S}$ of Tepic, along road between Tepic and Compostela, 18.X.1970, G. L. Webster 15738 (MEXU). Municipio Escuinapa, route 15, ca. $88 \mathrm{~km}$ SE of Escuinapa, just N, 12.VII.1966, $R$. $W$. Cruden 1049 (MEXU). Municipio Tepic, $1 \mathrm{~km}$ al SO de El Cuarenteño, camino a El Cora, o $4 \mathrm{~km}$ al $\mathrm{N}$ del entronque del camino El Cora - Palapitas, 16.V.1994, G. Flores F. 3465 (MEXU); 3 km al NO de Cuauhtémoc, 11.II.1992, A. Benitez P. 3715 (MEXU); km 4 de la carretera a San Blas, del entronque con la carretera Tepic - Mazatlán, 6.VIII.1987, O. Téllez V. 10719 (MEXU); $5 \mathrm{~km}$ al N de Tepic, 21. VI.1980, K. Neisiss s.n. (MEXU).

2) Salvia boegei Ramamoorthy, J. Arnold Arbor. 65: 137. 1984. TIPO: MÉXICO. Puebla, Puente de Dios Molcaxac, L. W. Boege 1933 (holotipo: MEXU!).

Plantas arbustivas, de 0.5-1.5 $\mathrm{m}$ de alto; tallos ramificados, entrenudos 2-5.5 cm, puberulentos cuando jóvenes, con tricomas simples, 0.1-0.2 mm de largo, glabrescentes en la ma- 
durez; peciolo 3-11 mm de largo, tomentoso, con tricomas simples, 0.1-0.2 mm de largo; lámina foliar, concolora, ovada, ocasionalmente orbicular, 2-4 cm de largo, 1-4 cm de ancho, ápice agudo, base cuneada, ocasionalmente redondeada, margen aserrado, haz bullado-rugoso, glabrescente, con tricomas simples, 0.1-0.2 mm de largo, envés glabrescente, con tricomas simples, $0.2 \mathrm{~mm}$ de largo; inflorescencia indefinida, con 1 o 3 racimos terminales, espiciformes, $6-17 \mathrm{~cm}$ de largo, con verticilastros a lo largo del raquis, distanciados 6-29 mm en la parte media, con 8-12 flores, raquis canescente, con tricomas simples, 0.1-0.4 mm de largo; brácteas ovadas, marrón claro, pronto deciduas, acuminadas, margen entero, 4-5 $\mathrm{mm}$ de largo, 2-3 $\mathrm{mm}$ de ancho, vilosas, con tricomas simples, 0.2-0.4 mm de largo; pedicelo 1.6-3.2 mm de largo, canescente, con tricomas simples, $0.2-0.4 \mathrm{~mm}$ de largo; cáliz tubular, 4-7 mm de largo, 2-4 mm de ancho, con labios caudados, el superior con 7 venas, indumento canescente, con tricomas simples, 0.4-0.8 mm de largo; corola azul a morada, 9-10 mm de largo; tubo ventricoso, 4-5 mm, con 2-4 papilas en su interior; labio superior galeado, 3.5-5 $\mathrm{mm}$ de largo, viloso, en el dorso con tricomas simples, glabro en el margen del labio; el inferior trilobado, 4-6 mm de largo, más largo que el superior; androceo con anteras elipsoides, dorsifijas y monotecas, filamento, 5.9-6.2 mm de largo, estaminodios 2; gineceo con estilo bífido, barbado, 9-9.2 $\mathrm{mm}$ de largo, rama anterior $1 \mathrm{~mm}$ de largo, rama posterior 1.5-2.1 mm de largo; mericarpos no vistos.

Distribución y ecología: Puebla. Bosque tropical caducifolio y matorral xerófilo. Altitud 1600 a $1800 \mathrm{~m}$. Floración de agosto a diciembre.

Salvia boegei se puede confundir con $S$. breviflo$r a$; ambas presentan láminas foliares ovadas, indumento glabrescente en el cuerpo vegetativo, canescente en la inflorescencia y ocasionalmente también en el envés de la lámina foliar. Se distinguen por el largo de las láminas foliares, en $S$. boegei no exceden los $4 \mathrm{~cm}$ de largo, mientras que en $S$. breviflora llegan hasta $7 \mathrm{~cm}$. Además, la pubescencia del cáliz presenta tricomas más largos en S. boegei $(0.4-0.8 \mathrm{~mm})$ que en $S$. breviflora $(0.2-0.5 \mathrm{~mm})$.
Material examinado. MÉXICO. Puebla, municipio Epatlán, km 10 de la brecha que va de Epatlán a Huehuetlán, 10.IX.1983, R. Medina L. 704 (MEXU). Municipio Huatlatlauaca, la barranca de Tentzo, $12 \mathrm{~km}$ al O de Molcaxac, carretera a Huatlatlauaca, 22.X.1986, P. Tenorio L. 12188 (ENCB, MEXU). Municipio Huehuetlán el Grande, alrededores de Santa Ana Otzolotepec, 23.XII.1982, R. Medina L. 509 (MEXU). Municipio Molcaxac, lomas de la Sierra Tentzo, frente a la cañada de Zoquiac $(6 \mathrm{~km}$ de Molcaxac), 28.X.1983, R. Medina L. 744 (MEXU); Puente de Dios, al NO de Molcaxac, 23.VIII.1984, P. Tenorio L. 7092 (MEXU); rancho San Antonio, $10 \mathrm{~km}$ al NO de Molcaxac, brecha a Huatlatlauca, 15.X.1984, $P$ Tenorio L. 7668 (MEXU). Municipio San Juan Atzompa, San Juan Atzompa, 20.XII.1982, R. Medina L. 453 (MEXU, UAMIZ). Municipio Tepexi de Rodríguez, paraje Cuixosto, también conocido como Agua Chiquita, terrenos del Sr. Vicente Ramos Flores, cercanía al río Axamilpa, 18.X.1999, E. Guizar N. 4720 (MEXU); 2 km en línea recta al NO de Tepexi de Rodríguez, 10.XI.1999, $P$. Carrillo R. 6549 (MEXU).

3) Salvia breviflora Moc. y Sessé. ex Benth., Labiat. Gen. Spec. 274. 1833. TIPO: MÉXICO. México, M. Sesséy Lacasta y J. M. Mociño 216 (holotipo: F!, isotipos: F!, MA!) = Salvia albicans Fernald, Proc. Amer. Acad. Arts Sci. 36: 501. 1901. TIPO: MÉXICO. Guerrero, Iguala, C. G. Pringle 8430 (holotipo: GH!, isotipos: BM!, CM!, HBG!, JE!, P!, R!, US!) = Salvia nelsonii Fernald, Proc. Amer. Acad. Arts Sci. 35(25): 527-528. 1900. TIPO: MÉXICO. Puebla, Acatlán, A. Nelson 2005 (holotipo: GH!, isotipo: US!).

Plantas arbustivas, de 0.5 a $3 \mathrm{~m}$ de alto; tallos ramificados, entrenudos 1-7 cm, puberulentos cuando jóvenes, con tricomas simples, 0.1-0.2 mm de largo, glabrescentes en la madurez; peciolo $3.5-20 \mathrm{~mm}$ de largo, tomentoso, con tricomas simples, 0.1-0.3 mm de largo; lámina foliar, concolora, ovada, ocasionalmente orbicular, $2-7 \mathrm{~cm}$ de largo, 1.4-4.2 cm de ancho, ápice agudo, base cuneada, ocasionalmente redondeada, margen aserrado, haz bulla- 
do-rugoso, glabrescente, con tricomas simples, 0.1-0.2 $\mathrm{mm}$ de largo, envés glabrescente con tricomas simples, 0.2-0.4 mm de largo; inflorescencia indefinida, con 1 o 3 racimos terminales, espiciformes, $5-14 \mathrm{~cm}$ de largo, con verticilastros a lo largo del raquis, distanciados 6-20 mm en la parte media, con 8-12 flores, raquis canescente, con tricomas simples, 0.1-0.4 mm de largo; brácteas ovadas, marrón claro, pronto deciduas, acuminadas, margen entero, 4.5-13.5 mm de largo, 2.5-6.5 mm de ancho, canescentes, con tricomas simples, $0.2-0.4 \mathrm{~mm}$ de largo; pedicelo de 1-3.6 mm de largo, canescente, con tricomas simples de 0.1-0.5 mm de largo; cáliz tubular, 4.5-8 $\mathrm{mm}$ de largo, 2.5-5.5 mm de ancho, con labios caudados; el superior con 5-7 venas, canescente, con tricomas simples, 0.2-0.5 $\mathrm{mm}$ de largo; corola azul, morada o blanca, 7-12 mm de largo; tubo ventricoso, de (3)4.5-6 mm de largo, con 2-4 papilas en su interior; labio superior galeado, 3-7 $\mathrm{mm}$ de largo, viloso, en el dorso con tricomas simples y glabro en el margen del labio; el inferior trilobado, 3-7 mm de largo, más largo que el superior; androceo con anteras elipsoides, dorsifijas y monotecas, filamento de 4.2-7 mm de largo, estaminodios 2; gineceo con estilo bífido, barbado, 8.2-11.2 mm de largo, rama anterior 0.7-1.1 $\mathrm{mm}$ de largo, rama posterior 1.4-2.5 $\mathrm{mm}$ de largo; mericarpos no vistos.

Distribución y ecología: Guerrero, Morelos y Puebla. Bosque tropical caducifolio. Altitud 1050 a $2100 \mathrm{~m}$. Floración de julio a diciembre.

Usos: A esta especie se le conoce como Nah en Náhuatl o Becerrosiuitle en Comancoapan, municipio de San Juan Tetelcingo, Guerrero. Se le utiliza picada sobre las heridas de becerros provocadas por murciélagos, para matar los gusanos que crecen en las mismas ( $\mathrm{A}$. Villa $\mathrm{Ka}$ mel 457).

Salvia breviflora es parecida a $S$. boegei, véanse las diferencias morfológicas bajo $S$. boegei.

Material examinado. MÉXICO. Guerrero, municipio Buenavista de Cuéllar, Buenavista de Cuéllar,
10.X.1981, A. Ortega H. 88 (MEXU); camino empedrado a la antena de microondas del canal 13, km 19 al NE de Iguala, km 149 carretera de cuota México - Iguala, 28.XI.1986, A. Espejo 2764 (IEB); en la estación de Microondas de Cieneguilla, $11 \mathrm{~km}$ al SO de Buenavista de Cuéllar, 8.VI.1985, J. C. Soto N. 8917 (MEXU); paraje "La Tigra", $2.5 \mathrm{~km}$ al NO de San Pedro las Palmas, 6.X.1990, R. Razó 19 (MEXU). Municipio Chilpancingo de los Bravo, $1 \mathrm{~km}$ al NO de la desviación a Chichihualco, 23.VI.1990, J. C. Soto N. 13678 (MEXU); 1 km W of Chilpancingo, on the dirt road towards Amojileca; beyond Colonia Zapata, 11.VII.1987, O. Dorado 1732 (MEXU); $3 \mathrm{~km}$ de la carretera a Chichihualco, 17.IX.1976, E. Halbinger 398 (MEXU); Jalapa en el km 13.5 de carretera a Chichihualco, 5.X.1968, H. Kruse 2005 (IEB, MEXU); Joya del Zapote $6 \mathrm{~km}$ al $\mathrm{O}$ de la desviación a Chichihualco, la desviación está a $1.5 \mathrm{~km}$ al $\mathrm{N}$ de Chilpancingo, 24.VIII.1982, R. Torres C. 1141 (MEXU). Municipio Eduardo Neri, $2 \mathrm{~km}$ al SO de Xochipala, 15.VIII.1985, J. C. Soto N. 9842 (MEXU); $6 \mathrm{~km}$ al SO de Xochipala, 17.X.1983, J. C. Soto N. 5624 (MEXU); $34 \mathrm{~km}$ al NE de Filo de Caballo, camino a Xochipala, 8.IX.1983, E. Martínez S. 4310 (MEXU); $5 \mathrm{~km}$ al SO de Xochipala, camino a Filo de Caballo, 4.X.1988, E. Martinez S. 24059 (IEB); along the Milpillas - Atoyac road via Puerto del Gallo, 2.1 mi W of México highway 95 and $5 \mathrm{mi} \mathrm{E}$ of Xochipala, 15.X.1975, J. L. Reveal 4166 (MEXU); Amatitlán, 3.1 km al N, camino a Mazapa, 15.IX.1994, M. A. Monroy R. 452 (MEXU); el Palmar, $1 \mathrm{~km}$ al N, 14.V.1995, J. Calónico $S$. 1115 (MEXU); el Palmar, $1 \mathrm{~km}$ al N, 14.V.1994, J. Calónico S. 1126 (MEXU); loc. cit., 3.X.1994, J. Calónico S. 1438 (MEXU); en cañada del Zopilote, 11.VIII.1945, E. Hernández X. 2155 (MEXU); Mezcala, $14 \mathrm{~km}$ al SO, 21.VIII.1991, M. Luna F. 178 (MEXU); Mezcala, $15 \mathrm{~km} \mathrm{al}$ SO, 10.IX.1993, M. Martínez G. 828 (MEXU); road above Canyon de Zopilote $8 \mathrm{~km}$ E of Xochipala on way to Filo del Caballo from Milpillas, 9.XI.1973, D. E. Breedlove 35987 (MEXU). Municipio Iguala de la Independencia, $11 \mathrm{~km}$ al N. de Iguala por la autopista a México, 26.X.1979, S. D. Koch 7974 (MEXU); along México highway 95 between Taxco and Iguala, $17 \mathrm{mi} \mathrm{S}$ of Taxco, on $\mathrm{N}$ facing slopes 
adjacent to road, 16.X.1982, K. Peterson 777 (MEXU); Cañón de la Mano, entre los Amates y el Naranjo, 10 km al $\mathrm{N}$ de Iguala por el ferrocarril, cañón angosto con acantilados, 13.IX.1986, C. Catalán H. 104 (MEXU); Iguala Taxco highway, $7.8 \mathrm{mi}$ NE of Pemex station in Iguala and $8.2 \mathrm{mi} \mathrm{SW}$ of km $170 \mathrm{~S}$ of Taxco, 10.X.1959, C. R. Bell 17020 (MEXU). Municipio Leonardo Bravo, Leonardo Bravo, 10.XII.1997, J. Calónico S. 6928 (MEXU). Municipio Taxco de Alarcón, along México highway 95 between Taxco and Iguala, $17 \mathrm{mi} \mathrm{S}$ of Taxco, on $\mathrm{N}$ facing slopes adjacent to road, 16.X.1982, K. Peterson 6507 (IEB, MEXU); $14 \mathrm{mi}$ S of Taxco, road to Iguala, 4.XI.1970, $G$. L. Webster 16217 (MEXU); 8 mi E of Taxco, 8.VIII.1976, G. L. Webster 20708 (MEXU); orilla del río Xóchitl, camino a Taxco, IX.1934, E. Lyonnet 953 (MEXU); en el arroyo, 13.IX.1981, J. C. Soto N. 3132 (MEXU); Iguala de la Independencia, San Juan de la Unión, 12.XI.2005, L. Cervantes P. 49 (MEXU). Municipio Teloloapan, along road to Teloloapan at $\mathrm{km} 37.5$ from Iguala, 3.X.1980, H. H. Iltis 3089 (MEXU); Tepecoacuilco de Trujano, Comancoapan, San Juan Tetelcingo, 27.X.1990, A. Villa K. 457 (MEXU). Municipio Tetipac, $10 \mathrm{mi}$ N of Taxco, 21.VIII.1947, G. L. Webster 924 (MEXU), $10 \mathrm{mi}$ N of Taxco, 14.VIII.1953, $W$. E. Manning 531025 (MEXU). Municipio Tixtla de Guerrero, Atliaca, 24.VIII.1991, V. Nandi P. 73 (MEXU). Municipio Zumpango del Río, $2 \mathrm{~km}$ al $\mathrm{O}$ de Milpillas camino a Xochipala, 16.X.1983, E. Martínez S. 4884 (MEXU). Morelos, municipio Ajalpan, rocky, arid hill, $1 \mathrm{~km} \mathrm{~W}$ of Moyotepec on road to Tlaltizapán, 30.IX.1980, H. H. Iltis 3009 (MEXU). Municipio Atexcal, $12 \mathrm{~km}$ antes de Santa Catarina Tehuixtla, 5.X.1963, A. Gómez P. 1064 (MEXU). Municipio Jonacatepec, $1 \mathrm{~km}$ al N de Tlayca, 18.X.1986, E. Cabrera C. 12144 (MEXU); $3.7 \mathrm{~km}$ al S en desviación a Tlayca de la carretera Cuautla - Izúcar de Matamoros, 2.XI.2013, S. Lara C. 169 (EBUM). Municipio Tepoztlán, Tepoztlán, 12.X.1971, L. W. Boege 1997 (MEXU). Municipio Tlaltizapán, faldas del cerro de La Trinchera y Palmón Cuate, barranca honda, 13.X.1986, E. Estrada 1410 (MEXU). Municipio Xochiltepec, Xochiltepec, IX.1934, E. Lyonnet 955 (MEXU); loc. cit. Xochiltepec, XI.1933, E. Lyonnet 1083 (MEXU). Municipio Yautepec, Cañón de
Lobos, 26.X.1941, F. Miranda 1644 (MEXU); Cañón de Lobos, cerca de Yautepec, 19.IX.1954, Gold 696(MEXU); colonia Amador Salazar (Cañón de Lobos), 9.XI.1984, F. F. Gutiérrez M. 506 (MEXU). Puebla, municipio Izúcar de Matamoros; Matamoros, 20.X.1942, F. Miranda 2212 (MEXU); puerto las Palmas, $32.2 \mathrm{~km} \mathrm{~N}$ of Tehuitzingo on the road to Izúcar, 17.X.1985, B. Bartholomew 3004 (MEXU). Municipio Jolalpan, $2 \mathrm{~km}$ al $\mathrm{N}$ de San Pedro Las Palmas, 16.VII.1997, R. Razó 27A (IEB); 2 km al N de San Pedro las Palmas, 5.VII.1990, R. Razó 23 (IEB); cerro de Mitepec, ubicado al SO de Mitepec, 25.VII.1985, E. Guizar N. 102 (MEXU); Jolalpan $1.5 \mathrm{~km}$ al SO de San Pedro las Palmas, 15.IX.1990, R. Razó 24 (IEB).

4) Salvia evadens J. González y Castro, Nord. J. Bot. 34(4): 390-394. 2016. TIPO: MÉXICO. Jalisco, Sierra del Halo, R. McVaugh 16149 (holotipo: MICH!, isotipos: ENCB, IBUG). Descripción con base en la publicada por los autores González-Gallegos y Castro-Castro (2016) y observación de fotografías provistas por el primero de sus autores.

Hierbas perennes, de 0.4-0.6 m de alto; tallos con pubescencia hirsuta, con tricomas glandular-capitados; peciolo (3) 8-13 mm de largo, hirsuto; lámina foliar, concolora, deltoide a ovada, 1.9-4 cm de largo, 1.2-3 cm de ancho, ápice agudo a obtuso o redondeado, base truncada, redondeada, rara vez ligeramente oblicua, margen crenado a aserrado, haz bullado-rugoso hirsuto, con tricomas glandular-capitados concentrados en las venas, envés hirsuto, con tricomas glandular-capitados concentrados en las venas; inflorescencia indefinida, en racimo terminal, espiciforme, $17-25 \mathrm{~cm}$ de largo, con verticilastros a lo largo del raquis, con 4-12 flores, raquis hirsuto, con tricomas glandular-capitados; brácteas lanceoladas, marrón claro, deciduas, ápice agudo a caudado, truncado en la base, margen entero, ciliado, 2.7-4 mm de largo, 0.8$1.7 \mathrm{~mm}$ de ancho, hirsuta, con tricomas glandular-capitados; pedicelo 2.8-4 mm de largo, hirsuto, con tricomas glandular-capitados; cáliz tubular, 7-7.6 mm de largo, 3-5 $\mathrm{mm}$ de ancho, con labios agudos, el superior con 5 o 7 
venas, hirsuto, con tricomas glandular-capitados; corola azul obscura a morada, 17.7-23 mm de largo; tubo ventricoso, 13-16 mm de largo, sin papilas en su interior; labio superior galeado, 4.7-7 mm de largo, piloso; el inferior trilobado, (8.3)10.6-(9.8)10.8 mm de largo, más largo que el superior; androceo con anteras elipsoides, dorsifijas, y monotecas, filamento 8-8.9 mm de largo, estaminodios 2; gineceo con estilo bífido, piloso, 13.5-15 $\mathrm{mm}$ de largo; mericarpos ovoides, $1.6-1.90 \times 1-1.2 \mathrm{~mm}$, marrones claro, lisos, glabros.

Distribución y ecología: Jalisco. Bosque de Quercus. Altitud 1150 a 1400 m. Floración de agosto a octubre.

Salvia evadens es parecida a $S$. aequidistans, véanse las diferencias morfológicas bajo $S$. aequidistans.

5) Salvia dugesii Fernald, Proc. Amer. Acad. Arts Sci. 36: 500. 1901. TIPO: MÉXICO. Guanajuato, $A$. $A$. Dugés s.n. (holotipo: GH!). Fig. 6.

Plantas arbustivas, de 0.5-2 $\mathrm{m}$ de alto; tallos ramificados, entrenudos de 4.5-6 cm, vilosos cuando jóvenes, con tricomas dendríticos, 0.2-1 mm de largo, glabrescente en la madurez; peciolo 5-36 mm de largo, viloso, con tricomas dendríticos, 0.5-0.7 mm de largo; lámina foliar, discolora, ovada a ovado-lanceolada, 1.5-5.5 cm de largo, 1-3.5 $\mathrm{cm}$ de ancho, ápice agudo a obtuso, base truncada, redondeada a cordada, margen aserrado, haz bullado-rugoso, hírtulo, con tricomas dendríticos, 0.1-0.4 mm de largo, envés viloso, con tricomas dendríticos, 0.1-0.4 mm de largo; inflorescencia indefinida, con 1 o 3 racimos terminales, espiciformes, $2.5-29 \mathrm{~cm}$ de largo, con verticilastros a lo largo del raquis, distanciados $8-16 \mathrm{~mm}$ en la parte media, con 6-12 flores, raquis viloso, con tricomas dendríticos, 0.4-0.8 mm de largo; brácteas ovadas, marrón claro, pronto deciduas, acuminadas, margen entero, 1.9-3 $\mathrm{mm}$ de largo, 1-1.6 $\mathrm{mm}$ de ancho, vilosas, con tricomas dendríticos, 0.6-1 $\mathrm{mm}$ de largo; pedicelo de 2-4 $\mathrm{mm}$ de largo, canescente, con tricomas dendríticos, 0.3-0.6 mm de largo; cáliz tubular a campanulado, 4-8 mm de largo,
3-5 mm de ancho, con labios caudados; el superior con 6 venas, canescente, con tricomas dendríticos; corola azul a morada, 5-15 mm de largo, 4-6.5 de ancho; tubo ventricoso, 2.5-9 mm de largo, con 4 papilas en su interior; labio superior galeado, 2.5-7 mm de largo, viloso, en el dorso y margen del labio con tricomas glandular-capitados; el inferior trilobado, 3-8 mm de largo, más largo que el superior, ocasionalmente subiguales; androceo con anteras elipsoides, dorsifijas y monotecas, filamento $5-8 \mathrm{~mm}$ de largo, estaminodios 2; gineceo con estilo bífido, barbado, 7.6-12 mm de largo, rama anterior de 1-1.7 mm de largo, rama posterior de 1.4-4 mm de largo; mericarpos ovoides, 1.5-2 $\times 1-1.5 \mathrm{~mm}$, marrones claros, lisos, glabros, con papilas rojizas.

Distribución y ecología: Aguascalientes, Durango, Guanajuato, Jalisco, Michoacán, Oaxaca, Puebla y Querétaro. Bosque de Pinus-Juniperus, bosque de Quercus, bosque de Pinus, bosque tropical caducifolio y matorral xerófilo. Altitud 840 a 2400 m. Floración de marzo a diciembre.

En 1939, Epling sinonimizó a $S$. dugesii en $S$. melissodora, reconociendo dos formas de S. melissodora, una con tricomas dendríticos y la forma típica de $S$. melissodora con tricomas glandular-capitados. Sin embargo, tras la observación de los ejemplares de $S$. dugesii y $S$. melissodora, así como ejemplares tipo, se concluye que $S$. dugesii se debe mantener como especie distinta de $S$. melissodora. Salvia dugesii presenta pubescencia densamente incano-tomentosa, con tricomas dendríticos en todas sus estructuras (tallo, peciolo, brácteas, raquis, cáliz), a lo que Fernald (1901) no hace referencia en su publicación (Fig. 6). Adicionalmente en $S$. dugesii la pubescencia de brácteas y cálices es de tonalidades moradas a blanquecinas, mientras que en $S$. melissodora son blancos.

Material examinado. MÉXICO. Aguascalientes, municipio Tepezalá, ladera $\mathrm{N}$ cerro Mesillas, 21.VIII.2008, J. Martínez R. 1172 (IEB). Durango, municipio Mezquital, $3 \mathrm{~km}$ de Temohaya por el camino a 
Mezquital, 2.X.1984, M. González 1597 (IEB). Guanajuato, municipio Acámbaro, cerro El Paile, camino a la Chicharronera, 8.XI.1986, H. Díaz B. 3353 (IEB); cerca del poblado San Luis de los Agustinos, 21.VII.1987, Anónimo 4059 (IEB); $5 \mathrm{~km}$ al O de Irámuco, sobre el camino a Santa Ana Maya, 13.IX.1987, J. Rzedowski 44849 (IEB), 44882 (IEB). Municipio Comonfort, $6 \mathrm{~km}$ al E de Empalme Escobedo, 28.VII.1986, J. Rzedowski 40070 (IEB). Municipio Guanajuato, alrededores de Arperos, 24.VIII.1980, R. Galván 3579 (IEB, UAMIZ). Municipio Jerécuaro, $3 \mathrm{~km}$ al O de Jerécuaro, sobre la carretera a Coroneo, 9.XI.1986, J. Rzedowski 41709 (IEB). Municipio Juventino Rosas, Las Fuentes entrando por San Diego de los Dolores, 3.VI.2000, M. Martínez 6215 (IEB, MEXU). Municipio León, $4.5 \mathrm{~km}$ al NE de Alfaro, camino de terracería a Nuevo Valle, 19.XI.1988, R. Galván 3075 (ENCB, IEB, MEXU, UAMIZ); 7 km al N de León, por la carretera a San Felipe, 17.IX.2009, S. Zamudio 14541 (IEB), 14545 (IEB). Municipio Purísima de Bustos, los Tanques, cerca de El Palenque, 31.X.1988, R. Galván 3231 (IEB, MEXU). Municipio San Miguel de Allende, Alcocer, 29.VII.1987, R. Santillán 332 (IEB); Jardín Botánico el Charco del Ingenio, 6.XI.2002, W. L. Meagher 3200 (IEB); loc. cit., 18.IX.2013, E. I. Olvera M. s.n. (EBUM). Jalisco, municipio Acatic, barranca del Río Verde, bajando por Santa Rita, 9.XI.2008, M. Cházaro B. 9136 (IEB). Municipio Jocotepec, cerro Viejo, al NE de Zapotitán de Hidalgo, en el paraje Barranca del Agua, 29.X.1989, J. A. Machuca N. 6328 (IEB). Municipio Ixtlahuacán de los Membrillos, antena de microondas del cerro del Águila, $3.8 \mathrm{~km}$ al SE en línea recta de Mascuala, 24.IX.2012, J. González G. 1291 (IEB). Municipio Tlajomulco de Zúñiga, aproximadamente $2 \mathrm{~km}$ al NE de Tlajomulco, 12.XI.1998, A. Navarro M. 2304 (MEXU). Municipio Tolimán, 9-10 km al SO de Tolimán, 4-5 km al SO de San Pedro Toxín, 14.III.1990, R. Cuevas y L. Guzmán 3752 (IEB, MEXU). Michoacán, municipio Angamacutiro, vertiente $\mathrm{S}$ del cerro de Tres Reyes, cerca de Angamacutiro, 12.X.1994, J. Rzedowski 52690 (IEB). Municipio Churintzio, Las Pomas - Zináparo, 1.VIII.1984, J. N. Labat 1093 (MEXU); cerro Zináparo, $3.5 \mathrm{~km}$ al SE de Churintzio,
29.VIII.1992, I. Trejo 2477 (MEXU). Municipio Contepec, El Tambor, $3 \mathrm{~km}$ al E de Tepuxtepec, 25.X.1986, $S$. Zamudio 4964 (IEB, MEXU, UAMIZ); 1 km de la Presa Tepuxtepec - Contepec, 21.VIII.1991, H. Díaz B. 6860 (IEB). Municipio Cotija, entre El Paso y San Juanico, 28.X.1986, I. García 1674 (IEB). Municipio Cojumatlán de Régules, El Llano, 23.XI.2009, Y. Pantoja H. 755 (IEB). Municipio Epitacio Huerta, $1 \mathrm{~km}$ al O de Epitacio Huerta, 13.X.1990, J. Rzedowski 50226 (IEB). Municipio Jungapeo, en San Juan Purúa, 10.III.1984, J. C. Soto N. 6223 (IEB, MEXU); Los Picachos del Centro de la Muerte, $2 \mathrm{~km}$ SE del Cerrito, el cual se encuentra $10.5 \mathrm{~km}$ al SO de San Felipe carretera a Jungapeo, 29.X.1989, $R$. Torres C. 13446 (IEB). Municipio Tarímbaro, loma la Palobobera perteneciente y cerca de Uruétaro, 16.VIII.1986, J. S. Martínez M. 1613 (IEB); $2 \mathrm{~km}$ al N de Cuto del Porvenir, 26.VIII.1986, S. Zamudio 4401 (IEB). Municipio Tuxpan, ca. 1.7 mile NO of Tuxpan, near km post 129 on highway 15 to Morelia, 19.VIII.1975, G. Davidse \& J. Davidse 9784 (MEXU); Puerto de la Cantera, $5 \mathrm{~km}$ al O de Tuxpan carretera a Ciudad Hidalgo, 15.X.1989, $R$. Torres C. 13379 (IEB). Municipio Villa Jiménez, cerro E1 Brinco, 6.VIII.1990, E. Pérez C. 1535 (IEB); cerro la Alberca, 18.IX.1990, E. Pérez C. 1780 (IEB); cerro El Brinco del Diablo al NO de Villa Jiménez, 1.X.2008, E. Pérez C. 4916 (IEB); parte externa del cerro la Alberca al NE de los Espinos, 26.VIII.2003, S. Zamudio 12533 (IEB); 7 km al NE de Villa Jiménez, 2.VIII.1986, J. Rzedowski 40152 (IEB, MEXU). Oaxaca, distrito de Teposcolula, municipio San Juan Teposcolula, Mixtecal, enfrente de la fábrica de cal, 18.X.1984, T. P. Ramamoorthy 4735 (MEXU), $4735 b$ (MEXU), $4736 b$ (MEXU). Municipio San Pedro y San Pablo Teposcolula, cerro Los Tres Arbolitos, 500 m al O de Teposcolula, 12.X.1982, A. García M. 776 (MEXU). Distrito de Teotitlán, municipio Santa María Ixcatlán, poblado de Santa María Ixcatlán, 2.XI.2011, S. Rangel L. 1316 (MEXU). Municipio Teotitlán del Valle, $3 \mathrm{~km}$ al NE de Teotitlán, sobre el camino a Huautla de Jiménez, 29.VI.1987, A. González M. 3371 (MEXU). Puebla, municipio Ajalpan, $15 \mathrm{~km}$ al $\mathrm{N}$ de Ajalpan, brecha a San Luis del Pino, 2.XII.1991, A. S. Tovar 6385 (MEXU). 
Municipio Caltepec, cerro grande al SE de Caltepec, 7.XII.1983, P. Tenorio L. 5011 (MEXU); cerro el Gavilán, al SE de Caltepec, 3.VIII.1984, P. Tenorio L. 6765 (ENCB). Querétaro, municipio Arroyo seco, 4 km, al E de Arroyo Seco, carretera a Jalpan, 20.X.1982, P. Tenorio L. 2270 (MEXU). Municpio Cadereyta, Mesa la Providencia, 13.X.2004, R. Hernández M. 12140 (MEXU), 12141 (MEXU). Municipio Colón, granja Tolimán, 13.X.1993, Anónimo 10383 (IEB). Municipio El Marqués, $3 \mathrm{~km}$ al $\mathrm{N}$ de Presa del Carmen por el camino a la Laborcilla, 2.X.2002, L. Rincón N. 271 (MEXU); camino arriba de La Cañada, km 7 aproximadamente lado derecho yendo a Tequisquiapan, 2.VIII.1987, E. Argüelles 3009 (ENCB, IEB, MEXU). Municipio Ezequiel Montes, $1 \mathrm{~km}$ de Villa de Bernal, hacia Ajuchitlán, IX.2013, E. I. Olvera M.
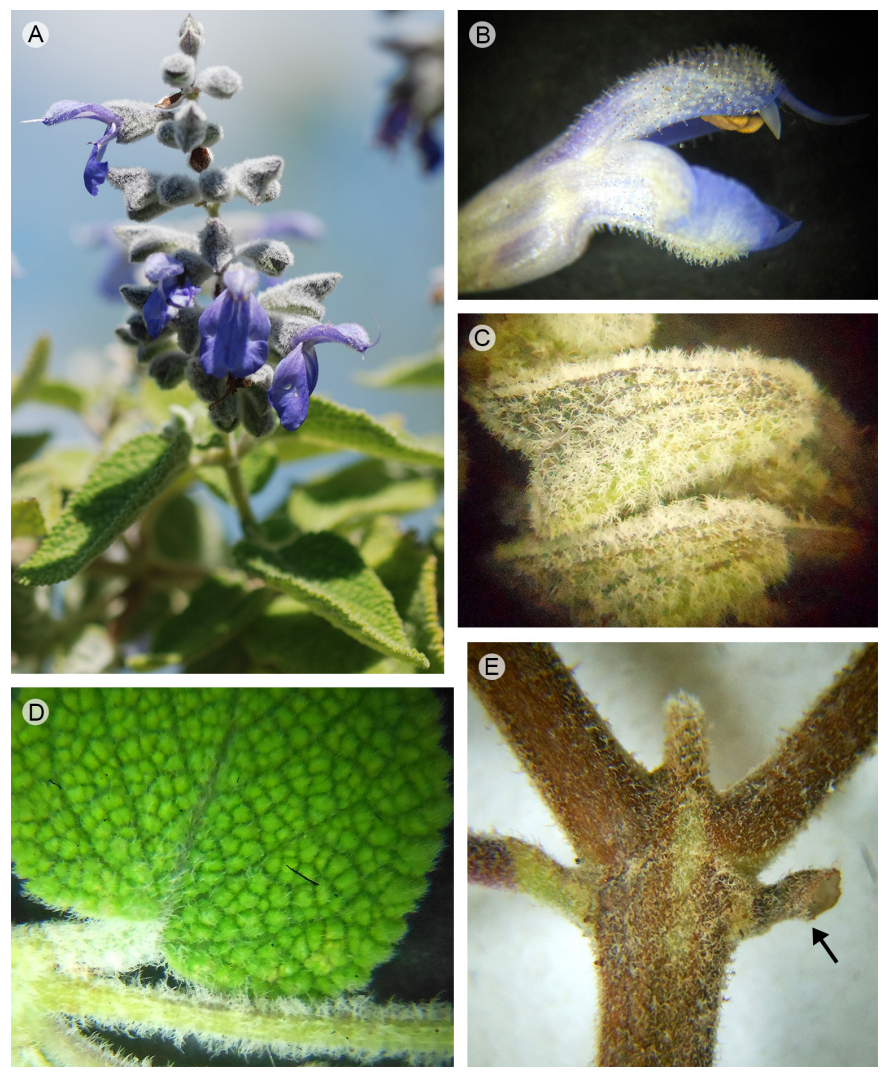

Figura 6: Salvia dugesii Fernald. A. inflorescencia; B. vista lateral de la corola mostrando tricomas glandular-capitados estipitados en ambos labios; C. vista lateral del cáliz mostrando los tricomas dendríticos; D. pubescencia del tallo y peciolo; E. articulación del peciolo en una prolongación del nudo (la flecha indica el carácter señalado). s.n. (EBUM) ranchería Barrera, cerca de Villa Progreso, 15.XI.1994, R. Hernández M. 10983 (IEB). Municipio Querétaro, Parque Nacional el Cimatario, 2.X.2002, J. G. Hernández O. 50 (IEB); Área Natural Protegida El Tángano, 22.VII.2004, P. Balderas 715 (IEB). Municipio San Juan del Río, cerca de San Juan del Río, 17.VIII.1905, J. N. Rose 9508 (MEXU); parte alta del cerro la Venta, al SO de San Juan del Río, 30.IX.2007, S. Zamudio 13914 (IEB).

6) Salvia fruticulosa Benth., Labiat. Gen. Spec. 721. 1835. TIPO: MÉXICO. Oaxaca, cerca de Oaxaca, G. Andrieux 151 (holotipo: K!, isotipos: G!, GH!, K!, P!, UC!) = Salvia conzatti Fernald. Proc. Amer. Acad. Arts Sci. 35 (25): 526. 1900. TIPO: MÉXICO. Oaxaca, El Parián, V. González 902 (holotipo: GH!).

Plantas arbustivas, de 0.5-2 $\mathrm{m}$ de alto; tallos muy ramificados, entrenudos de 0.5-7 cm, puberulentos cuando jóvenes, con tricomas dendríticos, de 0.1-0.3 mm de largo, glabrescentes en la madurez; peciolo de 4-9 $\mathrm{mm}$ de largo, canescente, con tricomas dendríticos, 0.1-0.2 mm de largo; lámina foliar, discolora, ovada a ovado-oblonga, 2-5 cm de largo, 1-2.4 cm de ancho, ápice agudo, base truncada, redondeada a cuneada, margen aserrado, haz bulladorugoso, glabrescente, con tricomas dendríticos, 0.1-0.2 mm de largo, envés canescente, con tricomas dendríticos, $0.1 \mathrm{~mm}$ de largo que cubren completamente la superficie; inflorescencia indefinida, con 1 o 3 racimos terminales, espiciformes, de $3-15 \mathrm{~cm}$ de largo, con verticilastros a lo largo del raquis, distanciados 6-13 mm en la parte media, con 8-12 flores, raquis canescente, con tricomas dendríticos, 0.1-0.3 mm de largo; brácteas ovadas, marrón claro, pronto deciduas, acuminadas, margen entero, 2.2-2.6 mm de largo, 1.6-2.6 mm de ancho, canescentes, con tricomas dendríticos, de 0.1-0.2 mm de largo; pedicelo de 1.5-4 $\mathrm{mm}$ de largo, canescente, con tricomas dendríticos, 0.2$0.3 \mathrm{~mm}$ de largo; cáliz tubular a campanulado, 3-6 mm de largo, 2-5 mm de ancho, con labios caudados; el superior con 7 venas, canescente, con tricomas dendríticos, 0.2-0.3 $\mathrm{mm}$ de largo; corola azul a morada, $8-14 \mathrm{~mm}$ de largo; tubo ventricoso, 5-7 mm de largo, con 2 papilas en su in- 
terior; labio superior galeado, 2.5-6 $\mathrm{mm}$ de largo, viloso, con tricomas dendríticos en el dorso; el labio inferior trilobado, 3.5-7 mm de largo, más largo que el superior, ocasionalmente sub-iguales; androceo con anteras elipsoides, dorsifijas y monotecas, filamento de $8.5 \mathrm{~mm}$ de largo, estaminodios 2; gineceo con estilo bífido, barbado, $11.5 \mathrm{~mm}$ de largo, rama anterior $1.2 \mathrm{~mm}$ de largo, rama posterior $2 \mathrm{~mm}$ de largo; mericarpos ovoides, $1.6 \times 1.3$ $\mathrm{mm}$, marrones claro, lisos, glabros.

Distribución y ecología: Oaxaca. Bosque de Pinus, bosque de Quercus, bosque de Pinus-Quercus, bosque de Pinus-Juniperus, bosque de Juniperus, matorral xerófilo y matorral con Juniperus. Altitud 1600 a 2370 m. Floración de junio a noviembre.

Salvia fruticulosa fue ubicada por Epling (1939) en la sección Tomentellae, por la pubescencia tomentosa, los tricomas dendríticos en el tallo y la presencia de glándulas sésiles en el cáliz; sin embargo, en este estudio se considera que la especie es más parecida a las de la sección Scorodoniae por tener el cáliz con lóbulos ligeramente agudos, lámina foliar ovada a ovado-oblonga y el tamaño de la flor entre 6 y $16 \mathrm{~mm}$ de largo. Estos caracteres coinciden con la diagnosis aquí propuesta para la sección Scorodoniae.

Salvia fruticulosa se podría confundir con $S$. dugesii y $S$. ramosa, por la presencia de tricomas dendríticos, pero a diferencia de éstas, los tricomas del cáliz de $S$. fruticulosa son dendríticos cortos (Fig. 1J). Además, presenta glándulas sésiles, rojas en el cáliz y ocasionalmente en la corola, mientras que $S$. dugesii y $S$. ramosa carecen de estas glándulas.

Material examinado. MÉXICO. Oaxaca, distrito de Etla, municipio Villa de Etla, Valle de Etla, 3.VIII.1919, C. Conzatti 3636a (MEXU), 3636b (MEXU). Distrito de Miahuatlán, municipio San Pablo Coatlán, $5 \mathrm{~km}$ al SE de la desviación a El Portillo de Santa María Coatlán, camino a Miahuatlán, 24.IX.1982, R. Cedillo T. 1841 (ENCB). Distrito de Nochixtlán, mu- nicipio Asunción Nochixtlán, 6 km SE de Nochixtlán, 18.X.1984, T. P. Ramamoorthy 4743 (MEXU); cerro La Cruz, 2.IX.1906, C. Conzatti $1562 a$ y 1562 c (MEXU); loc. cit., 20.VI.1907, C. Conzatti 1857 (MEXU), $1857 a$ (MEXU), $1857 b$ (MEXU). Distrito de Teotitlán de Flores Magón, municipio Santa María Ixcatlán, Agua Puerca, 2 km al S de Santa María Ixcatlán, 23.X.1991, P. Tenorio L. 17847 (MEXU). Distrito de Teposcolula, municipio San Juan Teposcolula, Mex. 125 direction Guadalupe Tixá, 11.VIII.2000, M. Crone 11 (MEXU); Mixtecal, enfrente de la fábrica de cal, 18.X.1984, T. P. Ramamoorthy 4733 (MEXU); cerro Los Tres Arbolitos, $1 \mathrm{~km}$ al O de Teposcolula, 11.VI.1985, R. Torres C. 6772 (MEXU); loc. cit., 12.X.1981, A. García M. 778 (ENCB), $778 a$ (MEXU), $778 b$ (MEXU); cerro el Peñasco al S de Teposcolula, 9.IX.1988, R. Torres C. 12320 (MEXU); 8 km al SO de Tamazulapan camino a Chilapa, 8.VIII.1981, D. H. Lorence $3726 a$ (MEXU); $2 \mathrm{~km}$ al NO de Teposcolula, camino a San Andrés Laguna, 9.VII.1981, A. García M. 451a (MEXU), $451 b$ (MEXU); arroyo de las Pozas Frías, $500 \mathrm{~m}$ al NO de Teposcolula, 2.VII.1981, A. García M. 454a, (MEXU), $454 b$ (MEXU). Municipio San Pedro y San Pablo Teposcolula, 2 km al NO de Teposcolula, camino a San Andrés Laguna, 9.VII.1981, $A$. García M. 451 (ENCB); arroyo de Las Pozas Frías, 500 $\mathrm{m}$ al NO de Teposcolula, 2.VII.1981, A. García M. 454 (ENCB); poblado de Teposcolula, 2.XI.1981, A. García M. 798 (ENCB, MEXU); distrito de Teposcolula, 5 $\mathrm{km}$ al S de San Felipe Ixtapa, camino a Chalcatongo Yodonda, 17.IX.1982, R. Cedillo T. 1717 (MEXU); 13 km al E de San Felipe Ixtapa, camino a Chalcatongo, 29.VII.1983, $R$. Torres C. 3333 (MEXU); cerca de $8 \mathrm{~km}$ al SO de Tamazulapan, camino a Chilapa, 8.VIII.1981, D. H. Lorence 3735 (MEXU); alrededores de Teposcolula, 14.XI.1985, T. P. Ramamoorthy 4782 (MEXU). Municipio Villa de Tamazulapan del Progreso, $5 \mathrm{~km}$ después de Tamazulapan, sobre carretera Tamazulapan - Chilapa, 13.XI.1985, T. P. Ramamoorthy 4774 (MEXU). Distrito de Tlaxiaco, municipio Heroica Ciudad de Tlaxiaco, 10 $\mathrm{km}$ al NE de Cuquilla, hacia Tlaxiaco, 1.XI.1985, R. Torres C. 7664 (MEXU). 
7) Salvia gonzalezii Fernald, Proc. Amer. Acad. Arts Sci. 1900. 35: 524. TIPO: MÉXICO. Oaxaca, El Parián, V. Gonzalez \& C. Conzatti 903 (holotipo: $\mathrm{GH}$ !, isotipo: MEXU!).

Plantas arbustivas; tallos poco ramificados, entrenudos 1-4 cm, glabrescentes, ocasionalmente con tricomas simples, muy cortos, 0.1-0.2 mm de largo; peciolo 5.5-10 mm de largo, viloso con tricomas simples, $0.5-0.7 \mathrm{~mm}$ de largo; lámina foliar, discolora, deltoide a ovada, $1-2.2 \mathrm{~cm}$ de largo, 0.9-1.8 cm de ancho, ápice agudo a obtuso, base truncada o cordada, margen aserrado, haz bullado-rugoso, glabrescente, con tricomas simples, $0.2-0.3 \mathrm{~mm}$ de largo, envés canescente, con tricomas simples, largos, de 0.3-0.4 $\mathrm{mm}$ de largo; inflorescencia indefinida, con racimo espiciforme, 6-17 cm de largo, con verticilastros a lo largo del raquis, distanciados $13-15.8 \mathrm{~mm}$ en la parte media, con 6-8 flores, raquis viloso, con tricomas glandular-capitados, 0.1-0.3 mm de largo, ocasionalmente largas, 0.3$0.5 \mathrm{~mm}$; brácteas no vistas; pedicelo 2.1-2.7 mm de largo, glabrescente, con tricomas glandular-capitados, 0.1-0.3 $\mathrm{mm}$ de largo; cáliz tubular, 6.3-7.4 mm de largo, 3.0-4.4 $\mathrm{mm}$ de ancho, con labios caudados, tricomas simples y glandular-capitados, 0.4-0.7 mm y 0.1-0.2 mm de largo, glabrescente; corola azul obscuro, 11 a $13.6 \mathrm{~mm}$ de largo; tubo ventricoso, 6.5-8.6 mm de largo; labio superior galeado, 4.5-5 mm de largo, viloso, en el dorso; el inferior trilobado, 3.5-5 mm de largo, más largo que el superior; androceo no visto; gineceo con estilo bífido, ligeramente barbado, 8-12 mm de largo, rama anterior 0.5-0.6 mm de largo, rama posterior 1.5-2.5 mm de largo; mericarpos ovoides, 1.8-2 × 1.1-1.3 mm de ancho, marrones claro, lisos, glabros.

Distribución y ecología: Oaxaca. Altitud 1200 a 1400 m. Floración en noviembre.

La similitud morfológica de $S$. pannosa y $S$. gonzalezii llevó a Epling (1939) a incluir a $S$. gonzalezii en la sinonimia de $S$. pannosa. Sin embargo, se deben mantener ambas especies como válidas, con base a que $S$. gonzalezii tiene láminas foliares ovado a deltoides, muy distintas a las ovado-lanceolado a lanceoladas que muestra S. panno$s a$. Es importante aclarar que las láminas foliares jóvenes también son distintas, en $S$. pannosa son ovado-oblongas, mientras que en $S$. gonzalezii son ovado a deltoides. Adicionalmente, aunque sus inflorescencias son muy similares, el número de flores es menor en $S$. gonzalezii que en S. pannosa (Cuadro 2).

Cuadro 2: Comparación entre Salvia pannosa Fernald y S. gonzalezii Fernald.

\begin{tabular}{lcc}
\hline & S. pannosa & S. gonzalezii \\
\hline Peciolo (mm) & $8-30$ & $5.5 .-10$ \\
Forma de lámina foliar (mm) & $\begin{array}{c}\text { ovado-lanceolada } \\
\text { a lanceolada }\end{array}$ & $\begin{array}{c}\text { deltoide a } \\
\text { ovada } \\
1-2.2\end{array}$ \\
Longitud de lámina foliar (cm) & $1.5-4.5$ & $0.9-0.8$ \\
Ancho de lámina foliar (cm) & $0.8-2.5$ & $0.3-0.4$ \\
Longitud de los tricomas del & 0.1 & $6-8$ \\
$\quad$ envés (mm) & & $13-15.8$ \\
Numero de flores por & $4-6$ & \\
$\quad$ verticilastro & & \\
$\begin{array}{l}\text { Distancia entre verticilastros, } \\
\text { en la parte media de la } \\
\text { inflorescencia }\end{array}$ & $10-33$ & \\
\hline
\end{tabular}

8) Salvia keerlii Benth., Labiat. Gen. Spec. 263. 1833. TIPO: MÉXICO. México, F. W. Keerl s.n. (holotipo: $\mathrm{K}$ !, isotipos: BR!, K!). Fig. 7.

Plantas arbustivas, de 1-3.5 m de alto; tallos muy ramificados, entrenudos $1.5-9 \mathrm{~cm}$, vilosos cuando jóvenes, con tricomas cortos $0.2 \mathrm{~mm}$, largos $0.4-0.6 \mathrm{~mm}$, en ocasiones solo de un tamaño, glabrescentes en la madurez; peciolo 5-36 mm de largo, viloso, con tricomas simples, cortos, $0.2 \mathrm{~mm}$ y/o largos, 0.4-0.7 $\mathrm{mm}$ de largo; lámina foliar, discolora, deltoide a ovada, ocasionalmente orbicular, 2-8 cm de largo, 1-4 cm de ancho, ápice agudo a obtuso, base cordada, truncada o redondeada, margen aserrado, haz bullado-rugoso, glabrescente, con tricomas simples, 
0.1-0.4 mm de largo, envés viloso, con tricomas simples, 0.1-0.4 mm de largo; inflorescencia indefinida, con $1 \mathrm{o}$ 3 racimos terminales, espiciformes, $4-21 \mathrm{~cm}$ de largo, con verticilastros a lo largo del raquis, distanciados 5-14 $\mathrm{mm}$ en la parte media, con 6-12 flores, raquis viloso, con tricomas simples, 0.2-0.5 mm de largo; brácteas ovadas, marrón claro, pronto deciduas, acuminadas, margen entero, 2-7.2 $\mathrm{mm}$ de largo, 2-4.4 $\mathrm{mm}$ de ancho, vilosas, con tricomas simples, 0.4-0.7 mm de largo; pedicelo 1.5-4 $\mathrm{mm}$ de largo, viloso, con tricomas simples, 0.3-0.6 mm de largo; cáliz tubular, 5.5-6 mm de largo, 2.5-3.1 mm de ancho, con labios caudados; el superior con 7 venas, viloso, con tricomas simples, (0.1)0.4-0.9 mm de largo; corola azul a morada, 8.5-14 mm de largo; tubo ventricoso, (3.3)5.1-7.9 mm de largo, sin papilas en su interior; labio superior galeado, 3-5.2 mm de largo, viloso, en el dorso y margen del labio inferior con tricomas simples; labio inferior trilobado, 3-7 mm de largo, más largo que el superior, ocasionalmente subiguales; androceo con anteras elipsoides, dorsifijas y monotecas, filamento 4-7 $\mathrm{mm}$ de largo, estaminodios 2; gineceo con estilo bífido, ligeramente barbado, 7.5-12 $\mathrm{mm}$ de largo, rama anterior 0.7-1.4 $\mathrm{mm}$ de largo, rama posterior (1)1.8-2.6 $\mathrm{mm}$ de largo; mericarpos ovoides, $1 \times 0.8 \mathrm{~mm}$, marrones claro, lisos, glabros.

Distribución y ecología: Estado de México, Guanajuato, Hidalgo, Nuevo León, San Luis Potosí, Querétaro y Tamaulipas. Matorral xerófilo, crasicaule y submontano, bosque de Pinus-Quercus y bosque de Quercus-Juniperus. Altitud 2170 a 3100 m. Floración de julio a diciembre.

Salvia keerlii es similar a $S$. dugesii y $S$. melissodora; las láminas foliares son deltoides a ovadas en $S$. keerlii, y ovada a ovada-lanceoladas en $S$. dugesii y $S$. melissodora. Sin embargo, S. keerlii se distingue por los tricomas simples del dorso de la corola, nunca glandularcapitados como se observan en $S$. dugesii y S. melissodo$r a$. La cobertura de estos tricomas en $S$. keerlii es total en cuerpo vegetativo y reproductivo, y no en $S$. dugesii y
S. melissodora. Adicionalmente, S. keerlii nunca presenta papilas en el interior de la corola.

Material examinado. MÉXICO. Estado de México, municipio desconocido, cerro de Los Pitos, Valle de México, 22.VII.1952, L. E. Matuda 21549 (MEXU). Guanajuato, municipio Atarjea, Aldama, 8.X.1977, S. Zamudio 2495 (ENCB, MEXU). Municipio Mineral de Pozos, la Mina Grande, 8 km al E de Pozos, 10.VIII.1989, E. Ventura V. 7068 (IEB); $3 \mathrm{~km}$ al O de Pozos, 31.X.1986, J. Rzedowski 41701 (IEB, UAMIZ); $6 \mathrm{~km}$ al O de Pozos, sobre el camino a la autopista, 10.IX.1987, J. Rzedowski 44686 (IEB, MEXU). Municipio San Luis de la Paz, hacienda el Kijay, $10 \mathrm{~km}$ al E de San Luís de la Paz, 12.X.1988, E. Ventura 6130 (IEB); loc. cit., 14.X.1988, E. Ventura 6160 (IEB); El Rincón, $12 \mathrm{~km}$ al E de San Luís de la Paz, 18.X.1988, E. Ventura 6210 (IEB); 3 km al SO de Pozos, 9.XI.1992, J. Rzedowski 51948 (IEB); cerca de El Prigón, 24.IX.1994, J. Rzedowski 52578 (IEB, MEXU). Municipio Victoria, cerro el Garbanzo por Victoria, 10.X.1991, E. Ventura 9670 (IEB). Hidalgo, municipio Ajacuba, Rincón del Gato, barranca al N del poblado Emiliano Zapata, vertiente S de la Sierra de Chicavasco, ejido E. Zapata, 20.VIII.1988, I. Díaz V. 33 (IEB, MEXU); cerro El Águila, vertiente S de la Sierra de Chicavasco, ejido San Nicolás Tecomatlán, 13. IX.1988, I. Díaz V. 186 (IEB, MEXU); "La Mesa“, meseta que está a $6 \mathrm{~km}$ al SE del poblado Tulancalco, vertiente $\mathrm{N}$ de la Sierra del Monte Alto de Temoaya, ejido Tulancalco, 15.IX.1988, I. Díaz V 268 (IEB, MEXU); poblado Emiliano Zapata, $19 \mathrm{~km}$ después de Ajacuba rumbo a San Agustín Tlaxiaca (de O a E), 10.VIII.1988, I. Díaz V. 393 (IEB, MEXU). Municipio Metepec, Metepec Station, 20.IX.1906, C. G. Pringle 10312 (MEXU); Metepec Station, 20.IX.1906, C. G. Pringle 10313 (MEXU). Municipio Mineral del Chico, Sierra de Pachuca, 21.VII.1901, J. N. Rose 5623 (MEXU). Municipio Pachuca de Soto, $2 \mathrm{~km}$ al NO de Pachuca, cerca del bordo, 11.X.1975, M. Medina C. 825 (MEXU); Pachuca de Soto, 4.V.1980, R. Hernández M. 4349 (MEXU); Sierra arriba Pachuca, 7.VIII.1948, F. Miranda 4462 (MEXU); 
entronque con la carretera a Nuevo Laredo, $1 \mathrm{~km}$ al O de Pachuca, 1.IX.1985, T. P. Ramamoorthy 4749 (MEXU); Sierra de Pachuca, 21.VII.1901, J. N. Rose 5623 (MEXU). Municipio Santiago de Anaya, $1.5 \mathrm{~km}$ al NO de Patria Nueva, 3.IX.1992, A. M. Soriano 252 (MEXU). Municipio Tlalnalapa, $3 \mathrm{~km}$ al $\mathrm{N}$ de Tlalnalapa, 21.X.1979, $C$. Escalera G. 103 (UAMIZ). Municipio Tula de Allende, near Tula, 5.X.1896, C. G. Pringle 6538 (MEXU). Municipio Villa de Tezontepec, $10 \mathrm{~km}$ al SE de Tezontepec, 19.XI.1971, F. Jiménez 175 (IEB). Municipio Zempoala, cerro de los Pitos, 10.VII.1976, A. Ventura A. 1771 (IEB, MEXU); loc. cit., 11.IX.1976, A. Ventura A. 2088 (IEB, MEXU); San Antonio, cerca de Tepa el Grande, 16. IX.1973, J. Rzedowski 31167 (IEB, MEXU); Zempoala, 1.VIII.1976, A. Ventura A. 1953 (IEB, MEXU). Municipio Zimapán, $5 \mathrm{~km}$ al NE de Trancas, hacia Nicolás Flores, 4.X.1980, R. Hernández M. 5029 (MEXU). Nuevo León, municipio Aramberri, $19 \mathrm{~km}$ del camino de la Escondida a Zaragoza vía Aramberri, 24.IX.1973, J. L. Reveal 3436 (IEB); Ascensión, La Escondida, 23.X.1993, J. C. Hinton 23671 (IEB, MEXU); cerro El Viejo, 1.X.1993, J. C. Hinton 23778 (IEB, MEXU). Municipio Doctor Arroyo, $12.2 \mathrm{mi}$. along dirt road turn off to ejido Capadero, just N of Doctor Arroyo. $34.5 \mathrm{mi}$ from Banco del Centro, Matehuala, Sierra Vieja, Cañada los Pozos, 20.X.1984, J. Sanders S. 1348 (MEXU), $1348 b$ (MEXU); $30 \mathrm{~km} \mathrm{NE}$ of Dr. Arroyo, $2.5 \mathrm{~km} \mathrm{NE}$ of San Antonio de Peña Nevada, O base of Cerro Peña Nevada, 3-5. VIII.1981, G. Nesom 4282 (ENCB, MEXU); Sierra El Soldado, camino San Antonio Peña, Nevada - Puerto Pinos, 24.VIII.1989, J. A. Villarreal 4941 (MEXU). Municipio General Zaragoza, Sierra del Soldado, camino San Antonio Peña Nevada - Puerto Pinos, 24.VIII.1989, J. Á. Villareal 14941 (MEXU). San Luis Potosí, municipio Ahualulco, $14 \mathrm{~km} \mathrm{~N}$ of Ahualulco along road from San Luis Potosí to Charcas, VIII.1988, D. E. Breedlove 69247 (MEXU). Municipio Cárdenas, Las Canoas, Sierra Madre Oriental, 6-7.VIII.1934, F. W. Pennell 17934 (MEXU). Municipio Catorce, Chihuahua desert, Sierra Catorce, $5 \mathrm{~km}$ E of La Maroma station, 14.IX.1978, B. A. Prigge 3284 (MEXU); Sierra Madre Oriental, 1934,
Anónimo 7290 (MEXU). Municipio Guadalcázar, 14 km al O de Guadalcázar, 17.XII.1986, P. Hiriart 541 (MEXU); $4 \mathrm{~km}$ E of Charco Blanco and on the road to Guadalcázar, 28.X.1985, B. Bartholomew 3561 (MEXU); 1 1/2 mi W of Guadalcázar, 11.XII.1957, R. Moran 6344 (MEXU); cerros que están $6 \mathrm{~km}$ al NE de Guadalcázar en las cercanías del Oro hacia Pozo de Acuña, 8.X.1996, $R$. Torres C. 14579 (IEB, MEXU); curva del Gato $6 \mathrm{~km}$ al NO de Guadalcázar hacia el crucero carretera San Luis Potosí - Matehuala, 15.X.2000, R. T. Colín 15970 (MEXU). Municipio Guadalcázar, curva del Gato $6 \mathrm{~km}$ al NO de Guadalcázar hacia el crucero carretera S.L.P. Matehuala, 15.X.2000, J. C. Montero 145 (MEXU); Abrego, Campamento Montemach, recorrido por el Cañón de los Yugos, el campamento está al NO de Abrego, $5 \mathrm{~km}$ al $\mathrm{N}$ de Guadalcázar, 23.IX.2012, R. Torres $C$. 17506 (MEXU). Municipio Las Charcas, along the Charcas road NW of San Luis Potosí, $10 \mathrm{mi} \mathrm{N}$ of Ahualulco and $22.5 \mathrm{mi} \mathrm{S}$ of Moctezuma, 25.IX.1973, J. L. Reveal 3451 (MEXU). Municipio Moctezuma, along the Charcas road NW of San Luis Potosí, $25 \mathrm{mi} \mathrm{N}$ of Ahualulco and $7.5 \mathrm{mi} \mathrm{N}$ of San José del Gritó, 23.IX.1973, J. L. Reveal y N. D. Atwood 3444 (MEXU). Municipio San Luis Potosí, 39 milles east of San Luis Potosí, 19.X.1966, W. Anderson y C. W. Laskowski 4079 (ENCB); 6 mi SE of highway 57-80 along road towards Cerritos just above Chihuahua desert, 6.IX.1971, J. Henrickson 6485 (MEXU); $8 \mathrm{~km}$ E of Mexican highway 57 along road to Guadalcázar, 28.VIII.1986, D. E. Breedlove y B. Anderson 63306 (MEXU); minas de San Rafael, VI.1911, C. Purpus 4869-a (MEXU). Municipio Santa Catarina, on México highway 70 to Ciudad Valles, $4.9 \mathrm{mi} \mathrm{W}$ of Santa Catarina, 18.XI.1975, K. M. Peterson 466 (MEXU). Querétaro, municipio Cadereyta de Montes, puerto el Tepozán, $20 \mathrm{~km}$ de Vizarrón, por la carretera a San Joaquín, 18.XI.1993, H. Díaz B. 7463 (IEB); 16 km al NE de Vizarrón, sobre el camino a San Joaquín, 11.X.1988, J. Rzedowski 47511 (IEB); cerros calizos al E de Vizarrón, 13.IX.1994, R. Hernández M. 10814 (IEB); $10 \mathrm{~km}$ al S de Vizarrón, 16.XI.1977, S. Zamudio 2414 (IEB); loc. cit., 16.IX.1977, S. Zamudio 2453 (IEB, MEXU); loc. 


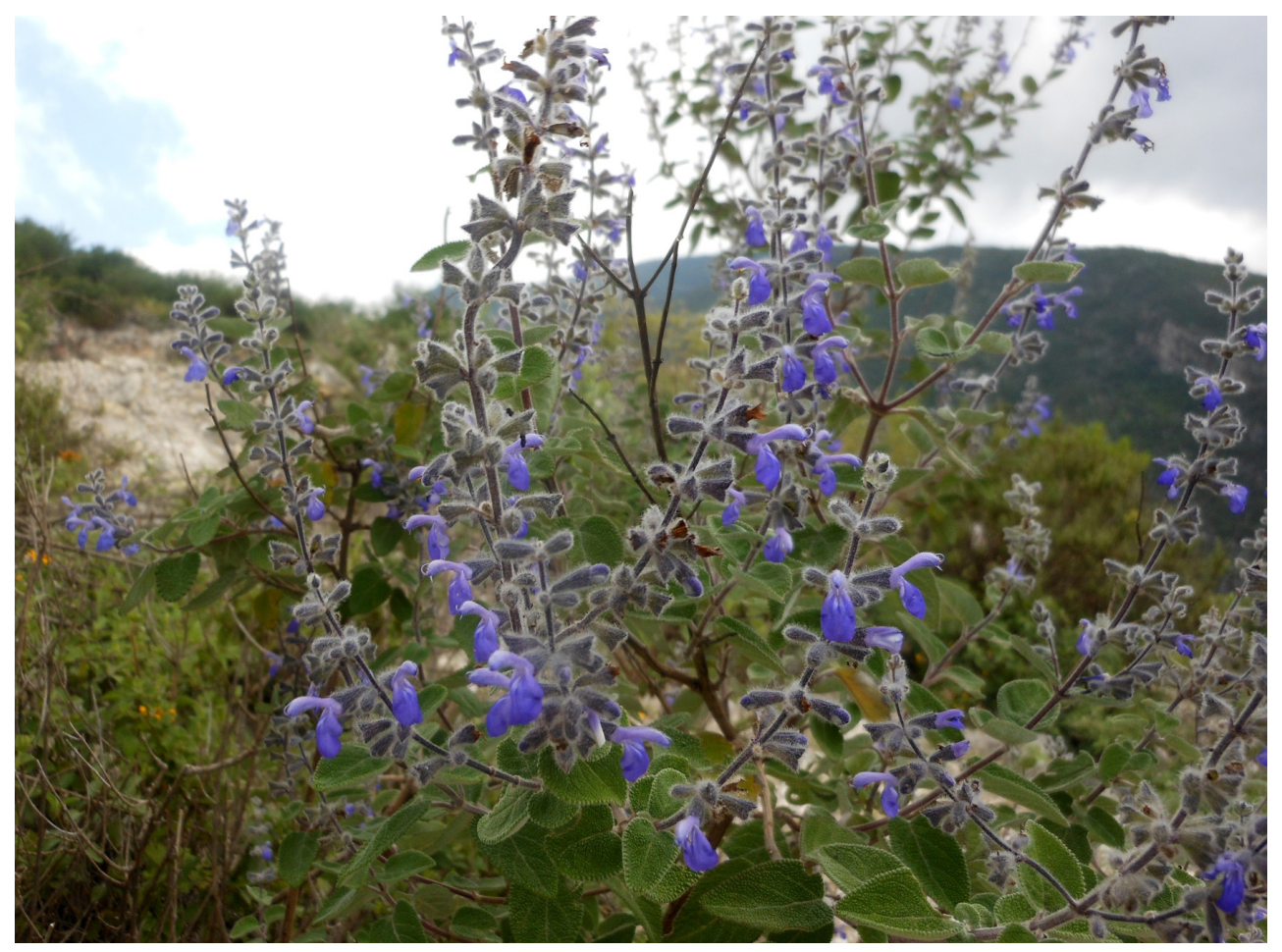

Figura 7: Salvia keerlii Benth., inflorescencia. (Foto: S. Zamudio).

cit., 26.VIII.1978, S. Zamudio 3187 (IEB, MEXU); ladera $\mathrm{O}$ de la Sierra Peña Azul, $2 \mathrm{~km}$ al SE del Jabalí, 12.VIII.1978, S. Zamudio 3030 (ENCB, IEB, MEXU); cañada de La Culebra, al NE de La Tinaja, 28.IX.1996, $S$. Zamudio 10006 (IEB); parador el Tepozán, 30.X.2002, S. Zamudio 12275 (IEB). Municipio Colón, camino entre Bernal y Santiago de Querétaro, 2. XI.2013, E. I. Olvera M. s.n. (EBUM). Municipio El Marqués, camino arriba de La Cañada, km 7 aproximadamente, lado derecho yendo a Tequisquiapan, 2.VIII.1987, E. Argüelles 3187 (ENCB, MEXU); $15 \mathrm{~km}$ al SE de Armadillo, 10. VIII.1956, J. Rzedowski 7965 (ENCB, MEXU). Municipio Landa de Matamoros, $9 \mathrm{~km}$ al NO de Madroño, sobre el camino a Laguna de Guadalupe, 18.IX.1997, J. Rzedowski 53521 (IEB). Municipio Peñamiller, 4 km al S del Río Blanco, 11.XI.1988, J. Rzedowski 47704 (IEB); Maguey Verde $17 \mathrm{~km}$, al SE de Pinal de Amoles, carretera Pinal de Amoles - Peñamiller, 22.X.1982, P. Tenorio L. 2345 (MEXU); $1.5 \mathrm{~km}$ al N de Maguey Verde, 8.X.1978, S. Zamudio 3488 (IEB, UAMIZ). Tamaulipas, municipio
Bustamante, $10 \mathrm{~km}$ al NE del Capulín, camino entre El Capulín y Felipe Ángeles, 27.VIII.1983, L. Hernández 648 (MEXU). Municipio Jaumave, $12 \mathrm{~km}$ al Sur de Ávila y Urbina, 23.IX.1984, F. González M. 14 (MEXU); 10 $\mathrm{km}$ después de Jaumave, rumbo a la Cd. de San Luis Potosí, o de otra forma $85 \mathrm{~km}$ al $\mathrm{O}$ de Cd. Victoria, 21.X.1983, A. Ortega H. 146 (MEXU); $12 \mathrm{~km}$ al sur de Ávila y Urbina, 23.IX.1984, F. González M. 14186 (MEXU); ca $33 \mathrm{~km}$ E of Jaumave; 2-3 km N of higway 70 on road to Bustamante, 6.X.1982, J. Henrickson 19089 (MEXU). Municipio Miquihuana, Miquihuana, 21.X.1978, F. Garza S. 4 (MEXU); 18 km al SO de Miquihuana, 15.VIII.1972, F. González M. 4745 (MEXU); $4 \mathrm{~km}$ al O de Miquihuana, 4.VIII.1941, L. R. Stanford 658 (MEXU). Municipio Palmillas, 14 km S de Palmillas, 28.IX.1986, A. Mcdonald 1005 (MEXU). Municipio Tula, $11 \mathrm{~km}$ E of Tula along road to Ocampo, 2.IX.1986, D. E. Breedlove 63606 (MEXU); $6 \mathrm{~km}$ al E del Sauz al NE de Tula, después de Francisco Medrano, 7.XII.1976, F. Guevara 10138 (MEXU). 
9) Salvia melissodora Lag. Gen. Sp. Pl. 2. 1816. MÉXICO. Localidad desconocida, M. Sessé y Lacasta y J. M. Mociño s.n (lectotipo: G!) = S. scorodoniaefolia Desf. ex Poir. 1817. Encycl. Suppl. 5: 46= S. scorodonia Desf. ex Poirt. en Benth. 1833 Labiat. Gen. Spec. 264, orth. var. $=$ Salvia microphylla Sessé y Mociño. Fl. Mex. 2, 9. 1894, nom. illeg. TIPO: MÉXICO. Localidad desconocida $=S$. scorodoniaefolia Poir. var. crenaea Fernald, Proc. Amer. Acad. Arts Sci. 35 (25): 524. 1900. TIPO: MÉXICO. Aguascalientes: K. T. Hartweg 164 (lectotipo: GH!, isolectotipos: K!, L!, $\mathrm{P} !)=$ Salvia rupicola Fernald, Proc. Amer. Acad. Arts Sci. 45(17): 420. 1910. TIPO: MÉXICO. Hidalgo, Ixmiquilpan, C. A. Purpus, 431 (holotipo: GH!, isotipos: MO!, UC!, US! RSA!), syn. nov. Fig. 8.

Plantas arbustivas, de $0.5-2 \mathrm{~m}$ de alto; tallos muy ramificados, entrenudos 2-4 cm, vilosos cuando jóvenes, con tricomas simples y glandular-capitados, 0.1-0.2 mm de largo u ocasionalmente dendríticos, glabrescentes en la madurez; peciolo 9-12 $\mathrm{mm}$ de largo, viloso, con tricomas simples y glandular-capitados, 0.3-0.5 mm u ocasionalmente dendríticos; lámina foliar, concolora, deltoide, ovada a ovado-lanceolada, 2-6 cm de largo, 1-3.5 cm de ancho, ápice agudo, base truncada o cordada, margen aserrado, haz bullado-rugoso, glabrescente, con tricomas simples y glandular-capitados, $0.2 \mathrm{~mm}$ de largo, envés viloso, con tricomas simples y glandularcapitados, $0.2 \mathrm{~mm}$ de largo; inflorescencia indefinida, con 1 o 3 racimos terminales, espiciformes, $4-16 \mathrm{~cm}$ de largo, con verticilastros a lo largo del raquis, distanciados 12-20 mm en la parte media, con 8-10 flores, raquis viloso, con tricomas simples y glandular-capitados, 0.2$0.5 \mathrm{~mm}$ de largo, ocasionalmente; brácteas marrón claro, pronto deciduas, ovadas, acuminadas, margen entero, 3.6-4.2 $\mathrm{mm}$ de largo, 2-2.6 $\mathrm{mm}$ de ancho, vilosas, con tricomas simples y glandular-capitados, $0.3-0.5 \mathrm{~mm}$ de largo; pedicelo de 2-2.5 mm de largo, viloso, con tricomas simples y glandular-capitados, 0.3-0.4 mm de largo, ocasionalmente dendríticos; cáliz tubular a campanulado, 3.7-8 $\mathrm{mm}$ de largo y 2.5-5 $\mathrm{mm}$ de ancho, con labios caudados, el superior con 7 venas, viloso, con tricomas simples y glandular-capitados; corola azul a morada, 6 a $17.5 \mathrm{~mm}$ de largo; tubo ventricoso, $3.5-11.5 \mathrm{~mm}$ de largo, con 4 papilas en su interior; labio superior galeado, 2.5-7.5 mm de largo, viloso, en el dorso y margen del labio con tricomas glandular-capitados; el inferior trilobado, 2.5-10 $\mathrm{mm}$ de largo, más largo que el superior, ocasionalmente subiguales; androceo con anteras elipsoides, dorsifijas y monotecas, filamento 6-7 $\mathrm{mm}$ de largo, estaminodios 2; gineceo con estilo bífido, ligeramente barbado, 11-13 mm de largo, rama anterior 1.1$1.5 \mathrm{~mm}$ de largo, rama posterior 3.5-3.8 $\mathrm{mm}$ de largo; mericarpos ovoides, $3.6 \times 2.2 \mathrm{~mm}$, marrones claro, lisos, glabros.

Distribución y ecología: Aguascalientes, Chihuahua, Ciudad de México, Durango, Estado de México, Guanajuato, Guerrero, Hidalgo, Jalisco, Michoacán, Nayarit, Oaxaca, Puebla, Querétaro, Veracruz y Zacatecas. Bosques de Juniperus, bosque de Quercus, bosque de Pi$n u s$, bosque tropical caducifolio y matorral xerófilo. Altitud 750 a 2600 m. Floración de marzo a enero.

Durante esta revisión se ha observado que $S$. melissodora presenta variación con respecto al tipo de tricomas del tallo, peciolo, raquis y pedicelo; algunos ejemplares tienen tricomas simples y glandular-capitados; otros cuentan con tricomas glandular-capitados y dendríticos y algunos tienen los tres tipos de tricomas simples, glandular-capitados y dendríticos.

Adicionalmente, se sinonimiza a $S$. rupicola con S. melissodora, de acuerdo con las observaciones. Los ejemplares de S. rupicola depositados en los herbarios y los originarios de la localidad tipo de S. rupicola (Ixmiquilpan, Hidalgo) no muestran variación, perteneciendo entonces a $S$. melissodora.

Material examinado. MÉXICO. Aguascalientes, municipio Calvillo, along Mex. highway 70 between Aguascalientes and Calvillo at km 25, 7.I.1983, J. S. Miller 356 (MEXU). Municipio Cosío, ladera E del cerro 
Mesillas, cerca del Salitrillo, 24.IX.2009, G. García 2178 (IEB). Municipio Nochistlán de Mejía, recorrido río de Santa Gertrudis (río de Abajo) Santuario Sr. de los Rayos, al NE de Tlachichila, 10.IX.2005, J. Martínez R. 504 (IEB). Chihuahua, municipio Batopilas, entre Quirare y la Bufa, 18.VII.1984, P. Tenorio L. 6568 (MEXU), 6581 (MEXU); barranca de Batopilas (N side), between La Bufa and Quirare, 24.I.1973, R. Bye 3296b (MEXU). Municipio Ocampo, ca. $1 \mathrm{~km}$ of $\mathrm{W}$ boundary of Parque Nacional "Cascada de Basaseachi" $16.2 \mathrm{~km}$ from the Cahuisori - Ocampo road on the road to Candameña, $5.6 \mathrm{~km}$ below Cruz Verde. Steep SE facing slope, 23.IX.1994, $R$. Spellenberg 12171 (MEXU). Ciudad de México, municipio desconocido, 6.IX.1903, C. G. Pringle 8744 (MEXU). Durango, municipio El Mezquital, $3 \mathrm{~km}$ al NO de Tamohaya, cerca al arroyo del Tempisque, 21.II.1985, S. Acevedo 168 (IEB); $14 \mathrm{~km}$ de El Mezquital, rumbo a Temoaya, 21.II.1985, S. Acevedo 176 (IEB, MEXU); km 10 del camino Agua Zarca - Temoaya, 12.II.1983, M. González E. 1157 (IEB). Municipio Peñón Blanco, canyon Cantero, Sierra Gamón, 21.IX.1948, H. S. Gentry 8374 (MEXU). Municipio Rodeo, $6 \mathrm{~km}$ al NO de las Higueras, 4.IX.1983, E. Torrecillas 166 (ENCB, MEXU); mina La Amparo 6 $\mathrm{km}$ al NO de Las Higueras, 5.IX.1983, P. Tenorio L. 4236 (MEXU). Estado de México, municipio desconocido, Valle de México, 21.VI.1865, L. Bourgeau 295 (ENCB, MEXU). Municipio Ecatepec de Morelos, $3 \mathrm{~km}$ al O de San Cristóbal Ecatepec; base de la Sierra de Guadalupe, 18.VIII.1974, J. Rzedowski 32127 (ENCB, MEXU); cerro de Santa Cruz, Sierra de Guadalupe, 24-25.X.1953, E. Matuda 29505 (MEXU), 29519 (MEXU); San Andrés, 5 km al SO de San Cristóbal Ecatepec, 6.IX.1970, J. Rzedowski 27631 (IEB, MEXU); Sierra de Guadalupe, entre Cuautepec y San Andrés, 14.VII.1973, S. Moreno G. 276 (IEB, MEXU). Municipio La Paz, cerro de la Caldera, Los Reyes, 15.VI.1954, D. B. Gold 725 (MEXU). Municipio Temascalcingo, Mesa del Venado, 26.IX.2004, J. M. Cruz 1255 (IEB, MEXU). Municipio Tenango del Valle, Tenango del Valle, $2 \mathrm{~km}$ del Monasterio "Santo Desierto" en el "Ballon del Diablo", 23.VI.1985, B. Esquivel s.n. (MEXU). Guanajuato, municipio Atarjea, El Banco 10 km al SO de Atarjea, 9.XI.1988, E. Ventura 6329 (IEB); Mangas Cuatas, 17.IX.1990, E. Ventura 8725 (IEB). Municipio Guanajuato, alrededores de Vaquería, $3 \mathrm{~km}$ al N de San José de Pinos, 24.VIII.1990, R. Galván 3587 (IEB, UAMIZ). Municipio Purísima de Bustos, San Nicolás del Palenque, 9.IX.1991, R. Galván 3741 (IEB, UAMIZ). Municipio San Miguel de Allende, cerro de las Tres Cruces, 27.VIII.1978, J. Kishler 386 (MEXU); loc. cit., 10.I.1980, J. Kishler 841 (MEXU); Jardín Botánico el Charco del Ingenio, 25.VII.1997, C. Glass 9158 (IEB); Cañón de las Colonias, 16.IX.1989, E. Argüelles 3197 (IEB, MEXU); "Rancho el Girasol", 22.IX.1988, A. Mora B. 927 (IEB). Municipio Silao, ladera E del cerro Cubilete, 14.VIII.2011, S. Zamudio 15173 (UAMIZ). Municipio Tierra Blanca, la Cieneguilla $8 \mathrm{~km}$ al E de Tierra Blanca, 15.VIII.1989, E. Ventura V. 7090 (IEB). Municipio Xichú, río Álamo, 15 km al N de Xichú, 8.IX.1989, E. Ventura 7260 (IEB). Guerrero, municipio Taxco de Alarcón, camino Taxco - Iguala, $6.29 \mathrm{~km}$ al $\mathrm{S}$ de Taxco, 13. XII.2008, J. C. Soto N. 27221 (EBUM). Hidalgo, a orilla de arroyo, al N de Atotonilco, 2.XI.1951-53, E. Matuda 29554 (MEXU); Mesa Doñana, 12.VIII.1981, R. Hernández M. 6353 (MEXU); San José, 7 km, al N de Atotonilco el Grande, 1.XI.1975, F. González M. 8329 (MEXU). Municipio Cardonal, barranca de Tolantongo, $3 \mathrm{~km}$ al N de Molanguito, 23.IX.1983, P. Hiriart 182 (MEXU). Municipio Ixmiquilpan, $3 \mathrm{~km}$ después de la desviación a Tolantongo, 30.VIII.1985, T. P. Ramamoorthy 4746 (MEXU); arriba de Molanguito, 30.VIII.1985, T. P. Ramamoorthy 4751 (MEXU); Ixmiquilpan, 4.XI.2013, E. I. Olvera M. s.n. (EBUM); Saliendo de Ixmiquilpan hacia Tasquillo, rumbo a la presa Madhó Corales, 4 .XI.2013, E. I. Olvera M. s.n. (EBUM). Municipio Metztitlán, 2.5 $\mathrm{km}$ al E de Metznoxtla, 20.X.2000, E. Guizar N. 5132 (MEXU); km 58 carretera Méx. 105 entre Pachuca y Huejutla, 16.IX.2011, A. Rodríguez 6441 (IEB). Municipio Mixquihuala de Juárez, Mixquihuala (en la peña), 5.V.1979, M. Porras s.n. (MEXU). Municipio San Agustín Metzquititlán, $3 \mathrm{~km}$ al $\mathrm{N}$ de Metztitlán, camino a Itztayatla, 9.IX.1993, R. Galván 4172 (MEXU); $5 \mathrm{~km}$ al SE de Venados, 5.VII.1972, F. González. M. 4149 (MEXU); al- 
rededor de La Casita, $21.2 \mathrm{~km}$ al NO de Atotonilco el Grande, 8.XI.1993, R. Galván 4160 (ENCB, MEXU); alrededores de Milpillas, 8: XI.1993, R. Galván 4163 (ENCB, MEXU); Barranca de Venados, 1.XI.1953, E. Matuda 29566 (MEXU). Municipio Tasquillo, "Cerro del Junquillo" al SO de Tasquillo, 2.VI.1982, P. Tenorio L. 499 (MEXU); Juchitlán, $3 \mathrm{~km}$ al NE de Tasquillo, 24.X.1997, R. Galván 4811 (IEB, MEXU, UAMIZ). Municipio Tecozautla, crucero de la carretera a Aljibe - La Sabina-Banzhá, 31.VII.2002, S. Rojas C. 188 (IEB); Tecozautla, 4.X.2002, S. Rojas C. 272 (IEB); El Epazote, 4.III.1992, V. M. Huerta B. 1424 (IEB, MEXU). Municipio Zacualtipán de Ángeles, $12 \mathrm{~km} \mathrm{~S}$ of Zacualtipán on highway 105, near el Banco, 22.IX.1985, S. A. Reisfield 1211 (MEXU). Municipio Zimapán, 13 km al NE de Zimapán, 6.IX.1979, R. Hernández M. 3694 (MEXU); Tinguendho, 8 km al S de Zimapán, 21.XI.1981, R. Hernández M. 6794 (MEXU); Tula near rte. 85 bridge, 15 mi SE of Zimapán, 4.VIII.1976, G. L. Webster 20627 (MEXU). Jalisco, municipio Colotlán, rancho El Saucillo, 23. III.1992, A. Rodríguez 785 (IEB); rancho El Saucillo, 23.III.1992, A. Rodríguez 2272 (ENCB, IEB). Municipio Jocotepec, camino de ascenso al cerro Viejo, por las Trojes, 9.IX.1987, A. Rodríguez C. 1007 (IEB, MEXU). Municipio Totatiche, rancho Acaspulco, $8 \mathrm{~km}$ al SO de Temastián, 28.VI.1991, A. Flores M. 2690 (MEXU). Michoacán, municipio Tuxpan, $14 \mathrm{~km}$ al SE de Ciudad. Hidalgo, carretera Ciudad Hidalgo - Zitácuaro, 22. VIII.1978, J. C. Soto N. 882 (MEXU). Nayarit, municipio Nayarit, $5 \mathrm{~km}$ al NO del poblado del cerro Cangrejo, en cañada, 20.X.1989, G. Flores F. 1636 (ENCB, MEXU); 5 $\mathrm{km}$ al NO del poblado del cerro Cangrejo, en cañada, 20.X.1989, G. Flores F. 1637 (MEXU). Oaxaca, municipio desconocido, localidad desconocida, 4.X.1895, $V$. González 53563 (MEXU); localidad desconocida, 9.X.1895, V. González s.n. (MEXU). Distrito de Cuicatlán, municipio San Juan Bautista Cuicatlán, 15.X.1920, C. Conzatti 4085 a y 4085 b (MEXU). Municipio San Juan Bautista Jayacatlán, 15.X.1920, C. Conzatti 4085 (MEXU); N of Jayacatlán along road towards Nacaltepec, 4.XI.1973, D. E. Breedlove 35939 (MEXU). Municipio
Santiago Nacaltepec, $50 \mathrm{~km} \mathrm{~N}$ of Telixtlahuaca on road to Tehuacán, 6.XI.1983, D. E. Breedlove 59832 (MEXU). Distrito de Juxtlahuaca, municipio Santiago Juxtlahuaca, $1.8 \mathrm{~km}$ de Santa Rosa, senda para Nican de la Soledad, carretera a San Antonio del Progreso, 7.XII.1996, J. I. Calzada 21547 (MEXU). Distrito de Silacayoapan, mumicipio Zapotitlán Lagunas, $15 \mathrm{~km}$ al NE de Zapotitlán Lagunas, brecha a Santiago Tamazola, 6.XII.1992, A. Campos V. 4877 (MEXU). Distrito de Sola de Vega, municipio Villa Sola de Vega, $50 \mathrm{~km}$ SO of Zimatlán on road to Puerto Escondido, 29.X.1974, D. E. Breedlove 39170 (MEXU). Distrito de Teotitlán, municipio Teotitlán del Valle, $3 \mathrm{~km}$ adelante de Teotitlán por la carretera a Huautla de Jiménez. 19.IV.1988, A. Salinas 4818 (MEXU); rocky outcrops along road to ruins of Dainzu just $\mathrm{S}$ of Mex 190, about $10 \mathrm{mi}$ SE of junction of Mex 190 and Mex 175 near Oaxaca, 2.VIII.1981, J. Utley 6649 (MEXU). Distrito de Zimatlán, municipio Zimatlán de Álvarez, 25. XI.1921, C. Conzatti 4316 (MEXU). Puebla, municipio Amozoc, cerro Tlaxcayo Grande, 23.I.2003, J. L. Contreras J. 7668 (MEXU). Municipio Amozoc, Parque Estatal Flor del Bosque, 16.XI.1993, M. Martínez R. 148 (MEXU). Municipio Chilchotla, cerro de Guadalupe, 10.X.1909, G. Nicolás s.n. (MEXU). Querétaro, municipio Amealco de Bonfil, el Batán, 8.VIII.1976, E. Argüelles 471 (ENCB, MEXU). Municipio Arroyo Seco, $5 \mathrm{~km}$ al NE de Purísima de Arista, 4.X.1999, M. A. Avalos 229 (IEB, MEXU); alrededores del puerto Concá, orilla de carretera, 4.X.1988, E. Carranza G. 986 (IEB); cerca a el Nogal, 18.X.1984, F. A. C. 57 (IEB). Municipio Cadereyta de Montes, El Mirador, $8 \mathrm{~km}$ al N de Vizarrón, 29. VI.1985, R. Fernández N. 2869 (IEB); Tecozautla, Zimapán, San Joaquín, fecha desconocida, M. Gómez P. M636 (IEB); Jardín Botánico Regional de Cadereyta Ing. Manuel González de Cosió, fecha desconocida, R. Hernández M. 9792 (IEB, MEXU); al E de Vizarrón, 31. VIII.1994, R. Hernández M. 10755 (IEB); 16 km al NE de Vizarrón, sobre el camino a San Joaquín, 11.X.1988, J. Rzedowski 96 (IEB); $2 \mathrm{~km}$ al SE de Pathé, sobre el camino a Tecozautla, 13.VI.1997, J. Rzedowski 53412 (IEB); 4 $\mathrm{km}$ al NE de San Javier, sobre el camino a Sombrerete, 
23.IX.2000, G. Ocampo 919 (IEB); barrancas al NO de Vizarrón, 16.X.2009, Y. Pantoja H. 739 (IEB); al E de Vizarrón, 3.XI.1968, H. Puig 3515 (ENCB); 5 mi by road. NE of Vizarrón, road to Jalpan, 8.XI.1970, G. L. Webster 16268 (MEXU); $10 \mathrm{~km}$ al S de Vizarrón, 16.IX.1977, S. Zamudio 2004 (ENCB, IEB, MEXU); al O de Vizarrón, 11.VIII.1977, S. Zamudio 2324 (IEB, MEXU, UAMIZ); La Laja, $8 \mathrm{~km}$ al NE de San Javier las Tuzas, 13.VIII.1977, S. Zamudio 2372 (IEB); 9 km al NE de Vizarrón, sobre la carretera a San Joaquín, 11.III.1978, S. Zamudio 2687 (ENCB, IEB, MEXU); 6 km al N de Vizarrón, 11.IX.1990, S. Zamudio 8050 (IEB); arroyo Carneros, $3.6 \mathrm{~km}$ al NO de la Mora, por la carretera a San Joaquín, 29.IX.1996, $S$. Zamudio 10037 (IEB); extremo N de la Presa Zimapán, antiguo camino a Rancho Nuevo, 29.IX.2007, S. Zamudio 13902 (IEB); 3 km al O de Vizarrón, 8.XI.2008, S. Zamudio 14240 (IEB); $5 \mathrm{~km}$ al O de San Javier las Tuzas, 17.XI.2010, S. Zamudio 14906 (IEB); 3 km al NE de San Javier las Tuzas, 26.IX.2012, S. Zamudio 15828 (IEB). Municipio Colón, alrededor del poblado El Zamorano,
29.IX.1993, R. Hernández M. 10319 (MEXU); $11 \mathrm{~km}$ al O de la Esperanza, 21.VII.1990, S. Zamudio 8008 (IEB). Municipio El Marqués, km 16-17 camino a Amealco, 3.IX.1977, E. Argüelles 807 (MEXU); camino arriba de La Cañada, 5.VIII.1979, E. Argüelles 1295 (ENCB, MEXU) loc. cit., 5.VII.1987, E. Argüelles 2979 (IEB, MEXU). Municipio Ezequiel Montes, subiendo un poco al monte Bernal, 14.VIII.1991, E. Argüelles 3346 (IEB, MEXU); $3 \mathrm{~km}$ al O de las Rosas, sobre la carretera a Tequisquiapan, 8.IX.1990, J. Rzedowski 50027 (IEB). Municipio Huimilpan, Los Cues, subiendo el monte, E. Argüelles 1672 (ENCB, MEXU); camino entre Querétaro - Huimilpan y carretera México Los Cues, km 8-9, 29. VI.1986, E. Argüelles 2534 (IEB). Municipio Jalpan de Serra, Jalpan, 12.X.1980, E. Argüelles 1485 (MEXU); 6-8 $\mathrm{km}$ de Tancoyol, camino a Zoyapilca, 28.III.1989, E. Carranza 1596 (IEB); $4 \mathrm{~km}$ al SE de Tancoyol, 16.II.1985, R. Fernández N. 2682 (IEB, MEXU). Municipio Landa de Matamoros, Matzacintla, $29 \mathrm{~km}$ al NE de Jalpan, 28. IV.1982, R. Hernández M. 7175 (IEB); Matzacintla, 29

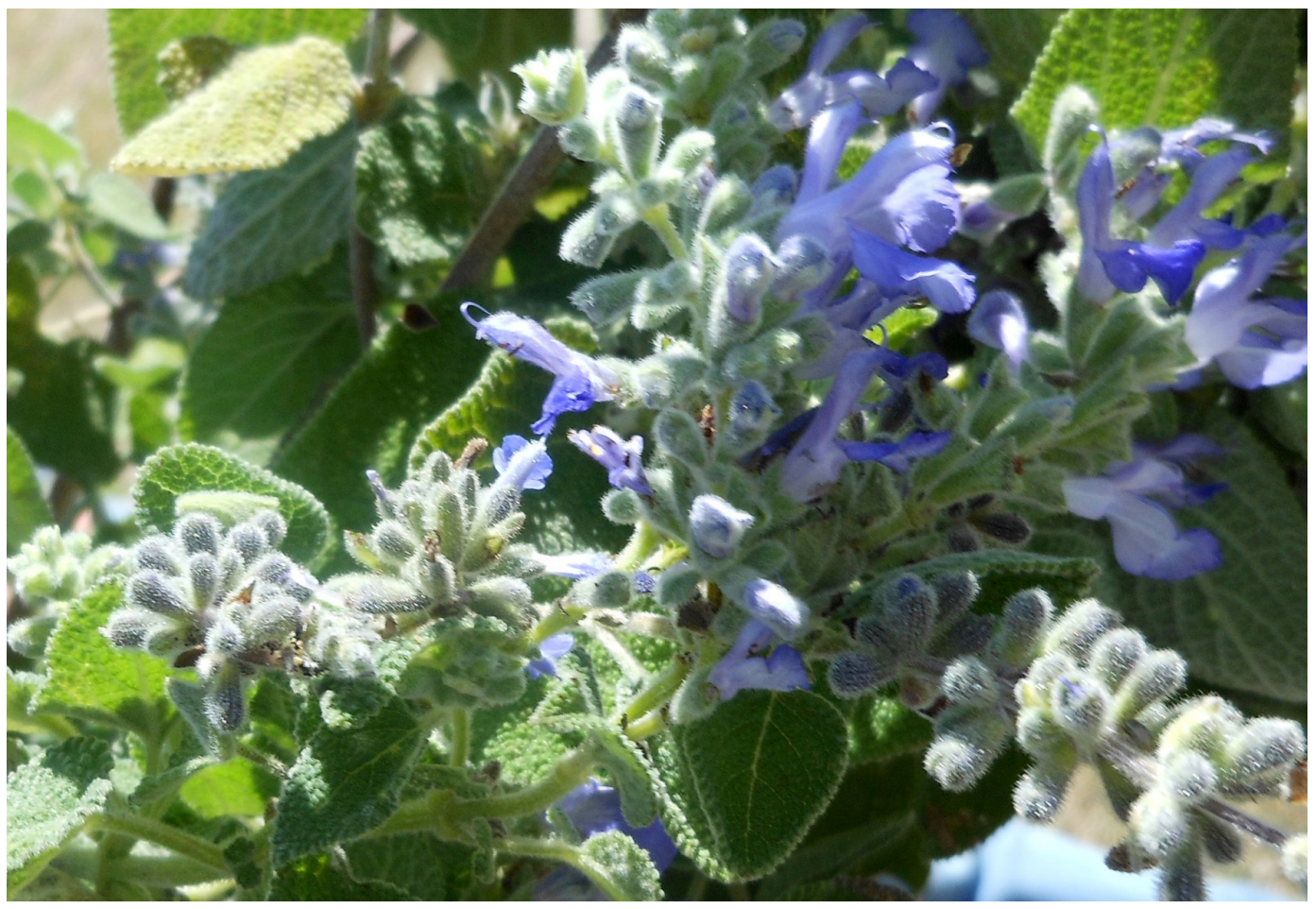

Figura 8: Salvia melissodora Lag, inflorescencia. (Foto: S. Zamudio). 
km al NE de Jalpan, 28.IV.1982, R. Hernández M. 7176 (MEXU). Municipio Peñamiller, Río Blanco, 30.V.2004, P. Balderas 593 (IEB); $3 \mathrm{~km}$ al $\mathrm{N}$ de Cuesta Colorada, 23.XII.1982, R. Hernández M. 9232 (MEXU); $2 \mathrm{~km}$ al NO de Camargo, 28.IX.1980, S. Zamudio 5768 (IEB); El Lindero, 23.IX.2002, S. Zamudio 12063 (IEB). Municipio Santiago de Querétaro, km 6, camino a Huimilpan, 27.VII.1984, E. Argüelles 2156 (IEB, MEXU); Parque Nacional El Cimatario, 17.VII.2003, P. Balderas 288 (IEB); El Nabo, 10.X.2002, L. Hernández 5023 (IEB, MEXU); cañada frente a Rancho Nuevo, delante de Los Cajones, 14.XI.2003, L. Hernández 5201 (IEB). Veracruz, municipio Huayacocotla, lado E de la barranca de Santiago, 23.X.1970, R. Hernández M. 41606 (MEXU). Zacatecas, municipio Juchipila, al O de Pueblo Viejo, cerro de Piñones, ladera E, camino al rancho de Antonio Benavides, 7.VIII.1998, J. J. Balleza C. 8712 (MEXU).

10) Salvia occidua Epling, Regni Veg. Beih. 110: 173. 1939. TIPO: MÉXICO. Oaxaca, San Miguel del Puerto, F. M. Liebmann 15697 (holotipo: C!).

Hierbas perennes, de 1-2 m de alto; tallos ramificados, entrenudos 3-7 cm, glabrescentes, ocasionalmente con tricomas simples, 0.1-0.2 $\mathrm{mm}$ de largo; peciolo de 5-7 $\mathrm{mm}$ de largo, glabrescente, tricomas simples, $0.3 \mathrm{~mm}$ de largo; lámina foliar lanceolado elíptica, $8-12 \mathrm{~cm}$ de largo, 2.5-4 cm de ancho, ápice agudo, base cuneada, margen aserrado, haz bullado-rugoso, glabrescente, con tricomas simples, $0.3 \mathrm{~mm}$ de largo, envés glabrescente, con tricomas simples, $0.3 \mathrm{~mm}$ de largo; inflorescencia indefinida, con 1 o 3 racimos terminales, espiciformes, $6-15 \mathrm{~cm}$ de largo, con verticilastros a lo largo del raquis, distanciados 6.5-7 mm en la parte media, con 8-12 flores, raquis viloso, con tricomas simples, $0.3 \mathrm{~mm}$ de largo; brácteas no vistas; pedicelo 1.6-2 mm de largo, viloso, con tricomas simples, $0.3 \mathrm{~mm}$ de largo; cáliz tubular, 4.5-5 $\mathrm{mm}$ de largo, 2.5 $-4 \mathrm{~mm}$ de ancho, con labios caudados; el superior con 5 venas, viloso, con tricomas simples, $0.4 \mathrm{~mm}$ de largo; corola blanca, 8-9 mm de largo; tubo ventricoso, 4.5-5.5 $\mathrm{mm}$, con 2 papilas en su interior; labio superior galeado,
3.5-4 mm de largo, viloso, en el dorso y margen del labio con tricomas simples; el inferior trilobado, 2.5-4.5 mm de largo, más largo que el superior; androceo con anteras elipsoides, dorsifijas y monotecas, filamento $5-5.5 \mathrm{~mm}$ de largo, estaminodios 2; gineceo con estilo bífido, ligeramente barbado, 8-9 $\mathrm{mm}$ de largo, rama anterior 0.7-0.8 $\mathrm{mm}$ de largo, rama posterior 1.5-2 $\mathrm{mm}$ de largo; mericarpos no vistos.

Distribución y ecología: Oaxaca. Bosque tropical subcaducifolio. Altitud 250 a 950 m. Floración de noviembre a diciembre.

Esta especie es la más distinta del grupo, es fácilmente reconocida por presentar laminas foliares lanceolado elípticas, grandes de $8-12 \mathrm{~cm}$, mientras que las demás especies nunca tienen las láminas lanceolado elípticas, más bien, presentan láminas deltoide, ovada a ovado lanceolado y el largo de las mismas es de 1-8 cm.

Material examinado. MÉXICO. Oaxaca, distrito Pochutla, municipio San Miguel del Puerto, en San Miguel del Puerto, carretera nueva rumbo al Faro, 18.XI.2000, F. López 441 (IEB); en San Miguel del Puerto, Cascadas de Copalitilla, 19.XI.1999, E. Martínez S. 33132 (IEB); en San Miguel del Puerto, 18.XII.2013, E. I. Olvera M. s.n. (EBUM).

11) Salvia pannosa Fernald, Proc. Amer. Acad. Arts Sci. 40: 54. 1904. TIPO: MÉXICO. Puebla, Tehuacán, C. G. Pringle 8593 (holotipo: GH!, isotipos: BM!, CM!, GH!, HBG!, K!, MEXU!, MIN!, MSC!, NY!, P!, RSA!).

Plantas arbustivas, de 0.5-1.5 $\mathrm{m}$ de alto; tallos poco ramificados, entrenudos 1 a $6 \mathrm{~cm}$, glabrescentes, ocasionalmente con tricomas simples muy cortos, de 0.1-0.2 mm de largo; peciolo 8-30 mm de largo, glabrescente con tricomas simples 0.1-0.2 mm de largo; lámina foliar, discolora, ovadolanceolada a lanceolada, $1.5-4.5 \mathrm{~cm}$ de largo, $0.8-2.5 \mathrm{~cm}$ de ancho, ápice agudo a obtuso, base truncada, en ocasio- 
nes redondeada o cordada, margen aserrado, haz bulladorugoso, glabrescente, con tricomas simples, 0.1-0.2 mm de largo, envés canescente, con tricomas simples, cortos, 0.1 $\mathrm{mm}$ de largo; inflorescencia indefinida, con 1 o 3 racimos terminales, espiciformes, $4-20 \mathrm{~cm}$ de largo, con verticilastros a lo largo del raquis, distanciados $10-33 \mathrm{~mm}$ en la parte media, con 8-12 flores, raquis glabrescente, con tricomas glandular-capitados, 0.1-0.2 mm de largo y glándulas sésiles esparcidas; brácteas ovadas, marrón claro, pronto deciduas, acuminadas, margen entero y ciliado, $2-5.5 \mathrm{~mm}$ de largo, 1.5-3.5 mm de ancho, con tricomas simples, 0.1-0.3 $\mathrm{mm}$ de largo, glabrescentes; pedicelo de (0.7)1.3-3.5 mm de largo, glabrescente, con tricomas simples y glandularcapitados, $0.1 \mathrm{~mm}$ de largo, ocasionalmente no glandularcapitados; cáliz tubular, 4.5-9.5 mm de largo, 2.5-4.5 mm de ancho, con labios caudados; el superior con 7 venas, con tricomas simples y glandular-capitados, 0.1-0.2 mm de largo y glándulas sésiles evidentes, glabrescente; corola azul a morada, 12.5-13 mm de largo; tubo ventricoso, 7.5$8.5 \mathrm{~mm}$ de largo, sin papilas en su interior; labio superior galeado, 3.5-5.5 mm de largo, viloso, en el dorso y margen del labio con tricomas simples; el inferior trilobado, 4.3-6 $\mathrm{mm}$ de largo, más largo que el superior; androceo con anteras elipsoides, dorsifijas, y monotecas, filamento 7.4-7.7 $\mathrm{mm}$ de largo, estaminodios 2; gineceo con estilo bífido, ligeramente barbado, 13-14 mm de largo, rama anterior 1-1.3 mm de largo, rama posterior 2.4-3.2 $\mathrm{mm}$ de largo; mericarpos no vistos.

Distribución y ecología: Oaxaca, Puebla y Veracruz. Matorral xerófilo, bosque tropical caducifolio y en la ecotonía con el bosque de Quercus y Pinus. Altitud 1350 a 2900 m. Floración de junio a diciembre.

Salvia pannosa se puede confundir con $S$. pericona por la inflorescencia laxa y la pubescencia en el envés de la lámina foliar, en ambas canescente. Se pueden distinguir por la forma de la lámina foliar, de ovado-lanceolada a lanceolada en $S$. pannosa y ovada en $S$. pericona, además del largo de los tricomas en el tallo y peciolo, más cortos en $S$. pannosa (0.1-0.3 mm) que en $S$. pericona $(0.6 \mathrm{~mm})$.
Material examinado. MÉXICO. Oaxaca, municipio desconocido, P. Tenorio L. 9456 (MEXU). Distrito de Coixtlahuaca, municipio Concepción Buenavista, cerro Cedro, al O de El Enebro, 22.X.1984, P. Tenorio L. 7964 (MEXU). Municipio Tepelmeme, cañada de Carrizalillo, cerro Verde, 17.VIII.1984, P. Tenorio L. 6958 (MEXU); Cerro Verde al N de Tepelmeme. 18.VII.1985, P. Tenorio L. 9285 (MEXU). Distrito de Cuicatlán, municipio San Pedro Jocotipac, Loma de en medio $5 \mathrm{~km}$ al SE de San Pedro Nodón brecha a San Pedro Jocotipac, 24.X.1991, P. Tenorio L. 17872 (MEXU). Distrito de Huajuapan, municipio Santa Catarina Zapoquila, Portezuelo Majada Grande, cerro Volcotepec al S de Membrillos, 9.XI.1986, P. Tenorio L. 12397 (MEXU); cañada al O de Membrillos, camino a el Arco, distrito Huajuapan, 14.IX.1991, P. Tenorio L. 17486 (MEXU). Distrito Huajuapan, Rincón del Tecolote, al NO de Guadalupe Membrillos, 17.X.1991, P. Tenorio L. 17668 (MEXU); cerro Gato, al E de Guadalupe Membrillos. 24.XI.1991, P. Tenorio L. 18218 (MEXU). Distrito Teposcolula, municipio Santiago Tejupan, $6 \mathrm{~km}$ al $\mathrm{E}$ de Tejupan por la carretera a Suchixtlahuaca. 8.IX.1990, A. Salinas T. 5616 (MEXU). Distrito de Tlacolula, municipio Teotitlán del Valle, Coixtlahuaca, Concepción Buenavista, base del cerro Pluma, base del cañón del puente Santa Lucía, aproximadamente sobre el km 99-100 de la carretera (cuota) Tehuacán - Oaxaca, 4.VI.1994, J. L. Panero 4025 (IEB). Puebla, municipio Atzingo, barranca de Tlacuilosto, al SO de San Juan Atzingo, 21.X.1986, P. Tenorio L.12147 (MEXU). Municipio Caltepec, $2 \mathrm{~km}$ al E de la intersección Tehuacán - Orizaba - Esperanza, 18.VII.1990, A. Salias T. 5454 (MEXU); barranca del Agua Fría, 1.5 $\mathrm{km}$ al O de San Luis Atotitlán, 5.VII.1983, P. Tenorio L. 4015 (MEXU); barranca del Agua Fría, $1.5 \mathrm{~km}$ al O de San Luis Atolotitlán, 13.VIII. 1983, P. Tenorio L. 6836 (IEB, MEXU); Rincón de la Hierba, La Mesa Chica al O de Caltepec, 20.IX.1984, P. Tenorio L. 7267 (MEXU); Rincón de la Hierba, La Mesa Chica al O de Caltepec, 8.X.1984, P. Tenorio L. 7616 (MEXU); cerro el Gavilán del Ejido, SO de Caltepec, 7.XI.1984, P. Tenorio L. 7994 (MEXU); Mesa de Buenavista, al N de Caltepec, 
11.XII.1983, P. Tenorio L. 5085 (MEXU); $7 \mathrm{~km}$ al E de Azumbilla, carretera a Vicente Guerrero, 16.IX.1991, P. Tenorio L. 17519 (MEXU). Municipio Nicolás Bravo, along Tehuacán - Orizaba highway just above Azumbilla, 18.VII.1961, C. E. Smith Jr. 3948 (MEXU); 2 km al N de Nicolás Bravo, 23.IX.1984, P. Tenorio L. 7300 (MEXU); $1 \mathrm{~km}$ al NO de Nicolás Bravo, 24.VI.1985, P. Tenorio L. 9079 (MEXU). Municipio San Antonio Cañada, San Esteban behind cerro Colorado, between Nacoxcalco and San Antonio Cañada, 13.VII.1961, C. E. Smith Jr. 4093 (MEXU). Municipio Tepanco de López, $7 \mathrm{~km}$ al NO de Teotepec, brecha a Nopala, 27.IX.1984, P. Tenorio L. 7463 (MEXU). Veracruz, municipio Acultzingo, Acultzingo, 18.VII.1986, P. Tenorio L. 11805 (MEXU).

12) Salvia paupercula Epling, Repert. Regni Veg., Beih. 110: 173. 1939. TIPO: MÉXICO. Puebla, Rancho Posada, F. Arsène 385 (holotipo: US!, isotipos: MPU!, UC!, US!, P!).

Plantas arbustivas; tallo ramificado, entrenudos $2-5 \mathrm{~cm}$, viloso cuando jóvenes, con tricomas dendríticos; peciolo 1-8 mm de largo; lámina foliar ovado-oblonga, $1.5-2 \mathrm{~cm}$ de largo, haz bullado-rugoso, ápice obtuso, base redondeada, margen aserrado; inflorescencia indefinida, con $1 \mathrm{o}$ 3 racimos terminales, espiciformes, con verticilastros a lo largo del raquis, distanciados 3.4-9 $\mathrm{mm}$ en la parte media, con 2-6 flores, raquis viloso, con tricomas glandular-capitados; brácteas marrón claro, pronto deciduas, ovadas, acuminadas, margen entero, 6-6.5 mm de largo, 2.5-3 mm de ancho; pedicelo 1.4-2.7 mm de largo, viloso, con tricomas glandular-capitados; cáliz tubular, 4-5.5 mm de largo y 2-2.5 mm de ancho, con labios caudados, viloso, con tricomas glandular-capitados; corola 5-8.5 mm de largo; tubo 5-5.5 mm de largo, con dos papilas en su interior; labio superior galeado, 2.4-2.8 mm de largo, en el dorso con tricomas glandular-capitados; el inferior trilobado, 3-3.4 $\mathrm{mm}$ de largo, más largo que el superior; androceo con anteras elipsoides, dorsifijas y monotecas, estaminodios 2 ; gineceo con estilo bífido, ligeramente barbado, $6.8-8 \mathrm{~mm}$ de largo, rama anterior $0.5-0.7 \mathrm{~mm}$ de largo, rama pos- terior 1-1.2 mm de largo; mericarpos ovoides, 0.6-0.8 $\times$ 0.4-0.5 mm de ancho, marrones claros, glabros.

Aparte de la colecta de Arsène, de octubre de 1909, no se encontraron ejemplares de esta especie en ninguno de los herbarios visitados ni en viajes de colecta, por lo que no fue posible completar la descripción original, realizada por Epling. Sin embargo, se incluyen algunos caracteres adicionales, que se lograron evaluar en las fotografías de los isotipos.

Salvia paupercula se puede confundir con S. melissodora, por la forma de la lámina foliar ovada; aunque, en observaciones más detalladas, se aprecia que la lámina foliar es distinta en forma y tamaño; en $S$. melissodora es de ovada a ovado-lanceolada de 2 a $6 \mathrm{~cm}$ de largo y peciolos de 9 a $12 \mathrm{~mm}$ y en $S$. paupercula la lámina foliar es ovado-oblonga de 1.5 a $2 \mathrm{~cm}$ de largo y peciolos de 1 a $8 \mathrm{~mm}$.

13) Salvia pericona B.L. Turner, Phytologia 91(2): 260261. 2009. TIPO: MÉXICO. Oaxaca, Coixtlahuaca, cerro Pericón, $5 \mathrm{~km}$ al $\mathrm{N}$ de San Pedro Nopala, $A$. García 2342 (holotipo: TEX!).

Hierbas perennes, de 0.5-1 $\mathrm{m}$ de alto; tallos poco ramificados, entrenudos 5-9 cm, glabrescentes, con algunos tricomas simples, $0.6 \mathrm{~mm}$ de largo; peciolo $10-30 \mathrm{~mm}$ de largo, viloso, con tricomas simples, $0.7 \mathrm{~mm}$ de largo; lámina foliar discolora, deltoide a ovada, $1.5-5 \mathrm{~cm}$ de largo, 1-3 cm de ancho, ápice agudo, base cordada, margen aserrado, haz bullado-rugoso, glabrescente, con tricomas simples, $0.1 \mathrm{~mm}$ de largo, envés canescente, con tricomas simples, $0.1 \mathrm{~mm}$ de largo; inflorescencia indefinida, con racimo terminal, espiciforme, $5-16 \mathrm{~cm}$ de largo, con verticilastros a lo largo del raquis, distanciados 10-28 $\mathrm{mm}$ en la parte media, con 10-12 flores, raquis viloso, con tricomas simples, $0.1 \mathrm{~mm}$ de largo; brácteas ovadas, marrón claro, pronto deciduas, acuminadas, con margen entero y ciliado, $7.5 \mathrm{~mm}$ de largo, $6 \mathrm{~mm}$ de ancho, glabrescentes; pedicelo $3 \mathrm{~mm}$ de largo, viloso, con tricomas simples, 0.1 mm de largo; cáliz tubular, 8-10.5 mm de largo, 3-3.5 mm de ancho, con labios caudados; el superior con 7 venas, 
viloso, con tricomas simples, $0.1 \mathrm{~mm}$ de largo; corola blanca, ventricosa, $16 \mathrm{~mm}$ de largo; tubo ventricoso, 10 $13 \mathrm{~mm}$ de largo, sin papilas en su interior; labio superior galeado, 5-6 mm de largo, viloso, con tricomas simples en el dorso; el inferior trilobado, 4.5-6 mm de largo, más largo que el superior, ocasionalmente subiguales; androceo con anteras elipsoides, dorsifijas y monotecas, filamento 7.3-11 mm de largo, estaminodios 2; gineceo con estilo bífido, barbado, 13-14.2 mm de largo, rama anterior 0.9-1.5 $\mathrm{mm}$ de largo, rama posterior 2.2-2.8 $\mathrm{mm}$ de largo; mericarpos no vistos.

Distribución y ecología: Oaxaca. Ecotonía con el bosque de Quercus y matorral xerófilo. Altitud $2320 \mathrm{~m}$. Floración en julio.

Salvia pericona es similar a $S$. pannosa, véanse las diferencias morfológicas bajo $S$. pannosa.

Material examinado. MÉXICO. Oaxaca, distrito Teposcolula, municipio Tamazulapan, cerro Pericón, al NO de San Pedro Nopala, 6.VII.1986, P. Tenorio L. 11597 (IEB).

14) Salvia ramosa Brandegee, Zoë 5: 255. 1908. TIPO: MÉXICO. Puebla, Cerro de Mazize, C. A. Purpus 2578 (holotipo: UC!).

Plantas arbustivas, de $0.5-1.5 \mathrm{~m}$ de alto; tallos muy ramificados, entrenudos $0.5-4 \mathrm{~cm}$, vilosos cuando jóvenes, con tricomas dendríticos, 0.2-0.5 mm de largo, glabrescente en la madurez; peciolo 4.5-10 mm de largo, viloso, con tricomas dendríticos, 0.1-0.4 mm de largo; lámina foliar, discolora, ovada, 2-3.5 cm de largo, 1-2 $\mathrm{cm}$ de ancho, ápice agudo a obtuso, base truncada, redondeada o cordada, margen aserrado, haz bullado-rugoso, glabrescente, con tricomas simples y dendríticos, 0.1-0.2 mm de largo, envés canescente, con tricomas dendríticos, 0.1-0.2 $\mathrm{mm}$ de largo; inflorescencia indefinida, con 1-3 racimos terminales, espiciformes, 4-23 $\mathrm{cm}$ de largo, verticilastros a lo largo del raquis, dis- tanciados 7-11 mm en la parte media, con 8-12 flores, raquis viloso, con tricomas dendríticos, $0.2-0.5 \mathrm{~mm}$ de largo; brácteas ovadas, marrón claro, pronto deciduas, acuminadas, margen entero, 3.5-5 mm de largo, 2-3 mm de ancho, viloso, con tricomas dendríticos, 0.2-0.5 mm de largo; pedicelo 1-1.6 mm de largo, viloso, con tricomas dendríticos, 0.3-0.5 mm de largo; cáliz tubular a campanulado, 3.8-4.5 $\mathrm{mm}$ de largo, 2-3.6 $\mathrm{mm}$ de ancho, con labios caudados; el superior con 7 venas, viloso, con tricomas dendríticos, 0.3-0.8 mm de largo; corola azul a morada, 6.5-7.6 mm de largo; tubo ventricoso, 3-4.5 mm de largo, con 2-4 papilas en su interior; labio superior galeado, 2-3 $\mathrm{mm}$ de largo, viloso, en el dorso con tricomas dendríticos, que generalmente se mezclan con tricomas simples y glandular-capitados; el inferior trilobado, 2.5-5 mm de largo, más largo que el superior; androceo con anteras elipsoides, dorsifijas y monotecas, filamento de 3.7-4 $\mathrm{mm}$ de largo, estaminodios 2; gineceo con estilo bífido, barbado, 5.5-6 mm de largo, rama anterior 0.6-0.9 $\mathrm{mm}$ de largo, rama posterior 1.3-1.5 $\mathrm{mm}$ de largo; mericarpos ovoides, $1.5 \times 1 \mathrm{~mm}$, marrones claro, lisos, glabros.

Distribución y ecología: Oaxaca y Puebla. Matorral xerófilo y bosque de Pinus-Quercus. Altitud 1900 a 2100 $\mathrm{m}$. Floración de mayo a diciembre.

La similitud morfológica de $S$. ramosa y $S$. variana llevó a Turner (2009) a incluir a $S$. ramosa en la sinonimia de $S$. variana. Sin embargo, se deben mantener ambas especies como válidas, en base a que $S$. ramosa tiene corolas más pequeñas $(6.5-7.6 \mathrm{~mm})$ que $S$. variana $(9-14$ $\mathrm{mm}$ ) (Cuadro 2). Además, el dorso del labio superior de la corola de $S$. ramosa tiene tricomas dendríticos y ocasionalmente simples y glandular-capitados, mientras que $S$. variana nunca presenta tricomas dendríticos.

Material examinado. MÉXICO. Oaxaca, distrito del Centro, municipio San Antonio de la Cal, cerro San Antonio, 8.IX.1921, C. Cowxalli 4235 (MEXU). Distrito de Coixtlahuaca, municipio Concepción Buenavista, 
Cuadro 3: Comparación entre Salvia ramosa Brandegee y $S$. variana Epling.

\begin{tabular}{|c|c|c|}
\hline & S. ramosa & S. variana \\
\hline Pedicelo (mm) & $1-1.6$ & $1.2-3.5$ \\
\hline Longitud del cáliz (mm) & $3.8-4.5$ & $4.5-6.5$ \\
\hline Ancho del cáliz (mm) & $2-3.6$ & $3-4.5$ \\
\hline $\begin{array}{l}\text { Longitud de la corola } \\
\qquad(\mathrm{mm})\end{array}$ & $6.5-7.6$ & $9-14$ \\
\hline $\begin{array}{l}\text { Longitud del labio } \\
\text { superior (mm) }\end{array}$ & $2-3$ & $3-6$ \\
\hline $\begin{array}{l}\text { Longitud de labio } \\
\text { inferior (mm) }\end{array}$ & $2.5-3$ & $5.5-8$ \\
\hline $\begin{array}{l}\text { Tipo de tricomas sobre } \\
\text { el dorso del labio } \\
\text { superior de la corola }\end{array}$ & $\begin{array}{l}\text { tricomas dendríticos, } \\
\text { ocasionalmente } \\
\text { entremezclados simples } \\
\text { y/o glandular capitados. }\end{array}$ & $\begin{array}{c}\text { tricomas simples } \\
\text { y/o glandular } \\
\text { capitados }\end{array}$ \\
\hline
\end{tabular}

cerro La Torrecilla al O de El Enebro, 25.VIII.1984, P. Tenorio L. 7132 (MEXU), cerro Cedro, al O de El Enebro, 22.X.1984, P. Tenorio L. 7962 (MEXU); cerro Cedro, al O de El Enebro, 20.VII.1985, P. Tenorio L. 9408 (MEXU). Distrito de Huajuapan de León, municipio Huajuapan de León, La Reforma entre Huajuapan de León y Tamazulapan, 6.VII.1985, R. Torres $C$. 6657 (ENCB, MEXU). Distrito de Teotitlán, municipio Santa María Tecomavaca, $1 \mathrm{~km}$ al O de Pochotepec, 25.IX.1990, P. Tenorio L. 17205 (MEXU). Distrito de Tlacolula, municipio San Lorenzo Albarradas, $4.7 \mathrm{~km}$ al NE de San Bartolo Albarradas. Camino a Totontepec 7.VIII.1985, R. Torres C. 7014 (MEXU). Puebla, municipio Caltepec, Barranca Rincón del Guayabo (tributaria de Barranca de Coyomeapan), $5 \mathrm{~km}$ al S de San Luis Atotitlán, 6.XI.2011, P. Carrillo R. 6507 (IEB); La Mesa de Buenavista, al N de Caltepec, 11.XII.1983, P. Tenorio L. 5082 (IEB, MEXU); La Mesa de Buenavista, al N de Caltepec, 19.IX.1984, P. Tenorio L. 7262c (MEXU); cerro El Gavilán, al SE de Caltepec, 17.X.1984, P. Tenorio L. 7292 (MEXU); cerro El Gavilán, al SE de Caltepec, 17.X.1984, P. Tenorio L. 7729 (IEB, MEXU); El Trueno al SO de Caltepec, 18.V.1986, P. Tenorio L. 11289 (IEB, MEXU).
15) Salvia tenorioi Ramamoorthy ex B. L. Turner, Phytologia 91(2): 262-263, 2009. TIPO: MÉXICO. Puebla, Teontepec, $14 \mathrm{~km}$ al NO de Teontepec, brecha Nopala, P. Tenorio L. 10648 (holotipo: TEX!).

Plantas arbustivas, de $1 \mathrm{~m}$ de alto; tallos muy ramificados, entrenudos 2-6 cm, vilosos cuando jóvenes, con tricomas simples, 0.1-0.3 mm de largo, glabrescentes en la madurez; peciolo 3-7 mm de largo, viloso, con tricomas simples, 0.1-0.3 mm de largo; lámina foliar, discolora, ovada y ocasionalmente orbicular, $0.6-2 \mathrm{~cm}$ de largo, $0.5-1 \mathrm{~cm}$ de ancho, ápice agudo a obtuso, base truncada o redondeada, margen aserrado, haz bullado-rugoso, glabrescente, con tricomas simples, 0.1-0.3 mm de largo, envés viloso, con tricomas simples, 0.1-0.3 mm de largo; inflorescencia indefinida, en racimo terminal, espiciforme, $5-13 \mathrm{~cm}$ de largo, verticilastros a lo largo del raquis, distanciados 3-5 mm en la parte media, con 4-6 flores, raquis viloso, con tricomas glandular-capitados, 0.2-0.3 mm de largo; brácteas no vistas; pedicelo $2.5-3 \mathrm{~mm}$ de largo, viloso, con tricomas simples, cortos, 0.1-0.3 mm de largo; cáliz forma tubular, 6-6.5 $\mathrm{mm}$ de largo, 2.5-3.5 $\mathrm{mm}$ de ancho, con labios caudados; el superior con 7 venas, viloso, con tricomas glandular-capitados, 0.1-0.3 mm de largo; corola amarilla a rojiza, 10-14 $\mathrm{mm}$ de largo; tubo ventricoso, 6.5-9.5 mm de largo, con 2 papilas en su interior; labio superior galeado, 4-4.2 mm de largo, viloso, con tricomas glandular-capitados en el dorso; el inferior trilobado, 3.6 a $4.6 \mathrm{~mm}$ de largo, más largo que el superior; androceo con anteras elipsoides, dorsifijas y monotecas, filamento 5-5.4 mm de largo, estaminodios 2; gineceo con estilo bífido, barbado, 11-12 $\mathrm{mm}$ de largo, rama anterior 6-9 mm de largo, rama posterior 1.3-1.6 mm de largo; mericarpos no vistos.

Distribución y ecología: Puebla. Bosque de PinusQuercus. Altitud 2480 m. Floración en septiembre.

Material examinado. MÉXICO. Puebla, mpio. Nicolás Bravo, cañada El Soldado, $3.8 \mathrm{~km}$ al S de Nicolás Bravo, 23.IX.1984, P. Tenorio L. 7330 (ENCB). 
16) Salvia variana Epling, Spec. nov. Regni. Veg. Beih. 110(2): 170-171. 1939. TIPO: MÉXICO. Puebla, San Luis Tultitlanapa, C. A. Purpus 3288 (holotipo: UC!; isotipos: F!, GH!, MO!, UC!, US!, NY!).

Plantas arbustivas, de 1-2.5 $\mathrm{m}$ de alto; tallos muy ramificados, entrenudos 1.5-6 cm, vilosos cuando jóvenes, con tricomas dendríticos, 0.1-0.3 mm de largo, glabrescentes en la madurez; peciolo 5-10 $\mathrm{mm}$ de largo, viloso, con tricomas dendríticos, 0.1-0.3 mm de largo; lámina foliar, discolora, deltoide a ovada, $2.5-4 \mathrm{~cm}$ de largo, $1.5-3 \mathrm{~cm}$ de ancho, ápice agudo a obtuso, base truncada, redondeada o cordada, margen aserrado, haz bullado-rugoso, glabrescente, con tricomas simples, 0.1-0.3 mm de largo, envés canescente, con tricomas dendríticos, 0.1-0.2 mm de largo; inflorescencia indefinida, con 1-3 racimos terminales, espiciformes, 4-15 $\mathrm{cm}$ de largo, con verticilastros a lo largo del raquis, distanciados 4-12 mm en la parte media, con 6-12 flores, raquis viloso, con tricomas dendríticos, 0.1-0.3 mm de largo; brácteas ovadas, marrón claro, pronto deciduas, acuminadas, margen entero, $5.5 \mathrm{~mm}$ de largo, $3.2 \mathrm{~mm}$ de ancho, viloso, con tricomas dendríticos, $0.3 \mathrm{~mm}$ de largo; pedicelo 1.2-3.5 $\mathrm{mm}$ de largo, viloso, con tricomas dendríticos, simples y bifurcados, 0.2-0.3 mm de largo; cáliz tubular a campanulado, 4.5-6.5 mm de largo, 3-4.5 $\mathrm{mm}$ de ancho, con labios caudados; el superior con 5-7 venas, viloso, con tricomas dendríticos, 0.3-0.6 mm de largo; corola rosa a guinda ocasionalmente azul, de 9 a $14 \mathrm{~mm}$ de largo; tubo ventricoso, 6-8 $\mathrm{mm}$ de largo, con 4 papilas en su interior; labio superior galeado, 3-6 mm de largo, viloso, en el dorso con tricomas simples y/o glandular-capitados y tricomas simples o glandular-capitados en el margen del labio; el inferior trilobado, 4.5-8 mm de largo, más largo que el superior; androceo con anteras elipsoides, dorsifijas y monotecas, filamento $7 \mathrm{~mm}$ de largo, estaminodios 2; gineceo con estilo bífido, ligeramente barbado, 9.5-13.5 mm de largo; rama anterior 1-1.2 $\mathrm{mm}$ de largo, rama posterior 2-3.5 mm de largo; mericarpos ovoides, $2.8 \times 1.8 \mathrm{~mm}$, marrones claro, lisos, glabros.

Distribución y ecología: Oaxaca y Puebla. Matorral xerófilo y bosque de Quercus con elementos de matorral xerófilo. Altitud 2100 a 2800 m. Floración de agosto a diciembre.

Salvia variana es similar a $S$. ramosa, véanse las diferencias morfológicas bajo $S$. ramosa.

Material examinado. MÉXICO. Oaxaca, distrito de Teposcolula, municipio Villa de Tamazulapan, cerro Pericón, NO de San Pedro Nopala, 13.XI.1985, T. P. Ramamoorthy 4777 (IEB). Municipio Teposcolula, enfrente de la fábrica de cal, cerca de Teposcolula, 14.XI.1985, T. P. Ramamoorthy 4782b (MEXU). Puebla, municipio Caltepec, La Mesa de Buena Vista, al N de Caltepec, 11.XII.1983, P. Tenorio L. 5075 (IEB); barranca del Agua Fría, $1.5 \mathrm{~km}$ al O de San Luis Atolotitlán, 3.VIII.1983, P. Tenorio L. 6839 (IEB); el Coro, $10 \mathrm{~km}$ al NO de Caltepec, ó $6 \mathrm{~km}$ al SE de Ecatepec, 14.VIII.1984, P. Tenorio L. 6866 (IEB). Municipio Tecamachalco, cerro Zapotlán, al $\mathrm{O}$ de Ometepec, 23.VIII.1984, P. Tenorio L. 7062 (IEB).

\section{CONTRIBUCIÓN DE AUTORES}

SILC diseño el estudio, asi como el asesoramiento de EIOM. BYBG revisó ejemplares del herbario IEB. EIOM reviso el material en los distintos herbarios, hizo colectas y realizó el escrito con la ayuda de SILC y BYBG. Todos los autores contribuyeron a la revisión y aprobación del manuscrito final.

\section{FINANCIAMIENTO}

Este estudio fue apoyado por la Coordinación de la Investigación Científica de la Universidad Michoacana de San Nicolás de Hidalgo (proyecto 8.16) a SILC, Instituto de Ecología, A.C. (Cuenta 20006) y a la Comisión Nacional para el Conocimiento y Uso de la Biodiversidad (CONABIO) a BYBG, beca de Consejo Nacional de Ciencia y Tecnología (CONACyT) (número 290575) a EIOM.

\section{AgRADECIMIENTOS}

Se agradece a Sergio Zamudio Ruíz, por facilitar las fotografías y sus invaluables aportaciones al manuscrito. A los 
encargados de los herbarios EBUM, ENCB, IEB, MEXU y UAMIZ, por las facilidades otorgadas para la consulta. A Jesús G. González-Gallegos, por facilitar la imagen del holotipo de Salvia evadens. A José Manuel Ramírez Amezcua por sus ilustraciones y a Damián Piña Bedolla por la preparación de la lámina. A Mariela Alejandre Solorzano por la enseñanza en la elaboración de los mapas. A los acompañantes de colecta y gente que nos invitó a colectar junto a ellos: Arnulfo Blanco, Anna Paizanni, Cesar Alfaro, Justino Olvera, Manuel Ramírez, Mario Veliz, Osvaldo Ramirez y Sergio Zamudio. A los miembros de la mesa sinodal de EIOM: Mario A. Espejo Serna, Gabriela Domínguez Vázquez, Miguel Martínez Trujillo, S. Zamudio Ruíz y Victor W. Steinmann, por sus enseñanzas y crítica revisión.

\section{LITERATURA CITADA}

Ahmed, S., Z. Kapadia e Y. Bardar. 1994. Antibacterial activity of Salvia santolinifolia. Fitoterapia 65: 271-272.

Bedolla-García, B. Y. 2012. Filogenia de Salvia secc. Polystachyae (Lamiaceae). Tesis de doctorado. Facultad de biología, Universidad Michoacana de San Nicolás de Hidalgo. Morelia, Michoacán, México. 165 pp.

Bentham, G. 1833-1836. Labiatarum genera et species: With their general history, characters, affinities, and geographical distribution. London, UK. 783 pp.

Bentham, G. 1876. Labiatae. In: Bentham, G. y J. Hooker (eds.). Genera Plantarum. Vol. 2. W. Pamplin. London, UK. Pp. 1160-1223.

Bentham, G. 1848. Labiatae. In: de Candolle, A. P. (ed.). Prodromus systematis naturalis regni Vegetabilis. Vol. 12. Treuttel \& Wurtz. Paris, Francia. Pp. 262-358.

Brandegee, T. S. 1908. New Species of Mexican Plants. Zoë: A biological Journal 5: 231-262.

Chen, H., F. Chen, Y. L. Zhang y J. Y. Song. 1999. Production of lithospermic acid B and rosmarinic acid in hairy root culture of Salvia miltiorrhiza. Journal of Industrial Microbiology \& Biotechnology 22: 133-138. DOI: http:// dx.doi.org/10.1038/sj.jim.2900624

Epling, C. C. 1939. A revision of Salvia, subgenus Calosphace. Repertorium Specierum Novarum Regni Vegetabilis, Beiheftenov. Regni Vegetabilis 110: 1-383.
Epling, C. C. 1940. Supplementary notes on American Labiatae. Bulletin of the Torrey Botanical Club Club 67: 509534.

Epling, C. C. 1941. Supplementary notes on American Labiatae II. Bulletin of the Torrey Botanical Club 68: 552-568.

Epling, C. C. 1944. Supplementary notes on American Labiatae III. Bulletin of the Torrey Botanical Club 71: 484-497.

Epling, C. C. 1947. Supplementary notes on American Labiatae IV. Bulletin of the Torrey Botanical Club 74: 512-518.

Epling, C. C. 1951. Supplementary notes on American Labiatae V. Brittonia 7: 129-142.

Epling, C. C. y M. E. Mathias. 1957. Supplementary notes on American Labiatae VI. Brittonia 8: 297-313.

Espejo, A. y T. P. Ramamoorthy. 1993. Revisión taxonómica de Salvia sección Sigmoideae (Lamiaceae). Acta Botanica Mexicana 23: 65-102.

Fernald, M. L. 1900. A synopsis of the Mexican and Central America species of Salvia. Proceedings of the American Academy of Arts and Sciences 35: 489-556.

Fernald, M. L. 1901. Some new spermatophytes. Proceedings of the American Academy of Arts and Sciences 36: 489506.

Fernald, M. L. 1904-1905. Some new species of Mexican and Nicaraguan dicotyledones. Proceedings of the American Academy of Arts and Sciences 40: 52-58.

Fernald, M. L. 1910. Little Known Mexican Plants. Proceedings of the American Academy of Arts and Sciences 45: 415-422.

Fernández-Alonso, J. L. 1995. Estudios en labiatae de Colombia II. Novedades en Salvia sect. Longipes Epl. Anales del Jardín Botánico de Madrid 53(1): 41-46.

Fernández-Alonso, J. L. 2006. Revisión taxonómica de Salvia sección Siphonantha (Labiatae). Anales del Jardín Botánico de Madrid 63(2): 145-157. DOI: http://dx.doi. org/10.3989/ajbm.2006.v63.i2.4

Fragoso, I. 2014. Análisis filogenético del complejo Salvia lavanduloides Kunth (Lamiaceae). Tesis de maestría. Universidad Nacional Autónoma de México. Ciudad de México, México. 202 pp.

Frodin, D. G. 2004. History and concepts of big plant genera. Taxon 53(3): 753-776. 
González, G., J. G. 2014. Revision of Salvia Subg. Calosphace sect. Membranaceae (Lamiaceae). Teleopea 16: 43-81. DOI: http://dx.doi.org/10.7751/telopea20147483

González, G. J. G. y A. Castro-Castro. 2016. Salvia evadens sp. nov. (Lamiaceae) from Sierra del Halo, Jalisco, México. Nordic Journal of Botany 34: 390-394. DOI: http://dx.doi. org/10.1111/njb.01091

Google. s.f. Mapa de México en Google maps. Recuperado en septiembre de 2016 de https:/www.google.com.mx/maps Grundmann, O., S. M. Phillips, I. Zadezensky y V. Butterweck. 2007. Salvia divinorum and Salvinorin A: an update on pharmacology and analytical methodology. Planta Medica 73: 1039-1046. DOI: http://dx.doi. org/10.1055/s-2007-981566

Guillén, M. D., N. Cabo y J. Burillo. 1996. Characterization of the essential oils of some cultivated aromatic plants of industrial interest. Journal of the Science of Food and Agriculture 70: 359-363. DOI: http://dx.doi.org/10.1002/ (SICI)1097-0010(199603)70:3<359::AID-JSFA512>3.0. $\mathrm{CO} ; 2-0$

Hijmans, R. J., L. Guarino y P. Mathur. 2012. DIVA-GIS. Version 7.5. A geographic information system for the analysis of species distribution data. Manual available http://www. diva-gis.org.

JSTOR. 2000-2016. JSTOR Global Plants, https://plants.jstor. org/ (consultado en sep 2016).

Kamatou, G. P. P., N. P. Makunga, W. P. N. Ramogola y A. M. Viljoen.2008. South African Salvia species: a review of biological activities and phytochemistry. Journal of Ethnopharmacology. 119: 664-672. DOI: http://dx.doi. org/10.1016/j.jep.2008.06.030

Lagasca, M. 1816. Genera et species plantarum quae aut novae sunt aut nondum recte cognoscuntur. Madrid, España. 35 pp.

Lamarck, J. B. y J. L. M. Poiret. 1817. Encyclopédie méthodique. Botanique. Supplement. Vol 5. Agasse. Paris, France. 707 pp.

McNeill J. Ch., F. R Barrier, H. M. Burdet, V. Demoulin, D. L. Hawksworth, K. Marhold, D. H. Nicolson, J. Prado, P. C. Silva, J. E. Skog y J. H. Wiersema. 2012. International Code of Nomenclature for algae, fungi, and plants (Melbourne Code): Adopted by the Eighteenth Interna- tional Botanical Congress Melbourne, Australia, July 2011. Regnum Vegetabile 154. Disponible en http://www. iapt-taxon.org/nomen/main.php

Peterson, K. 1978. Systematic studies of Salvia subgenus $\mathrm{Ca}$ losphace in section Farinaceae. Tesis de doctorado. University of Maryland. Washington D.C., USA. 191 pp.

Ramamoorthy, T. P. 1984a. A new species of Salvia (Lamiaceae) from Mexico. Brittonia 36(3): 297-299. DOI: http:// dx.doi.org/10.2307/2806530

Ramamoorthy, T. P. 1984b. Notes on Salvia (Labiatae) in Mexico, with three new species. Journal of the Arnold Arboretum 65: 135-143.

Ramamoorthy, T. P. y M. Elliott. 1998. Lamiaceae de México, diversidad, distribución, endemismo y evolución. In: Ramamoorthy, T. P., R. Bye, A. Lot y J. Fa. Diversidad biológica: Orígenes y distribución. Universidad Nacional Autónoma de México. Ciudad de México, México. Pp. 501-526.

Reisfield, A. S. 1987. Systematic studies in Salvia L. (Lamiaceae) with special emphasis on subgenus Calosphace (Benth.) Benth. Section Dusenostachys Epl. Tesis de maestría. University of Wisconsin. Madison, USA. 423 pp.

Rzedowski, J. 1978. Vegetación de México. Ed. Limusa. México, D.F., México. 505 pp.

Rzedowski, G. C. de, J. Rzedowski y colaboradores. 2010. Flora fanerogámica del Valle de México. Instituto de Ecología, A.C. y Comisión Nacional para el Conocimiento y Uso de la Biodiversidad. Pátzcuaro, Michoacán. 983 pp. Disponible en http://www.biodiversidad. gob.mx/publicaciones/librosDig/pdf/Flora_del_Valle_ de_Mx1.pdf

Santos, E. P. 1991. Genre Salvia L. Sous-genre Calosphace (Benth.) Benth. Secction Nobiles (Benth.) Epl. (Labiatae). Bradea 4: 436-454.

Santos, E. P. 1996. Revisión de la section Rudes (Benth.) Epling du genre Salvia L., sous-genre Calosphace (Benth.) Benth. (Labiatae). Candollea 51(1): 19-58.

Santos, E. P. 2004. Notes on Salvia sect. Secundae (Lamiaceae) and two new species from Brazil. Kew Bulletin 59: 285290. DOI: http://dx.doi.org/10.2307/4115862 
Santos, E. P. y R. M. Harley. 2004. Notes on Salvia section Nobiles (Lamiaceae). Kew Bulletin 59: 103-109. DOI: http://dx.doi.org/10.2307/4111080

Sessé, L. M. y J. M. Mociño. 1894. Flora Mexicana. Edition Secunda. Secretaria de Fomento. México, D.F., México. $240 \mathrm{pp}$.

Standley, P. C. y L. O. Williams. 1973. Flora of Guatemala. Fieldiana Botany 24(9): 1-946.

Torke, B. M. 2000. A revision of Salvia sect. Ekmania (Lamiaceae). Brittonia 52(3): 265-302. DOI: http://dx.doi. org $/ 10.2307 / 2666577$

Turner, B. L. 1996. Synopsis of section Axillaris of Salvia. Phytologia 81(1): 16-21.
Turner, B. L. 2008. Recension of Salvia sect. Farinaceae (Lamiaceae). Phytologia 90(2): 163-175.

Turner, B. L. 2009. Recension of Mexican species of Salvia sect. Scorodonia (Lamiaceae). Phytologia 91(2): 256-269.

Walker, J. B. 2006. A preliminary phylogenetic analysis of Salvia subgenus Calosphace. Tesis de doctorado. University of Wisconsin. Madison, USA. 132 pp.

Yagi, A., K. Fujimoto, K. Tanonaka, K. Hirai y S. Takeo. 1989. Posible active components of tanshen (Salvia miltiorrhi$z a$ ) for protection of the myocardium against ischemia-induced derangements. Planta Medica 55: 51-54. DOI: http://dx.doi.org/10.1055/s-2006-961824 